\title{
Aortic valve replacement using stented or sutureless/rapid deployment prosthesis via either full-sternotomy or a minimally invasive approach: a network meta-analysis
}

\author{
Kei Woldendorp ${ }^{1,2,3}$, Mathew P. Doyle ${ }^{2,3}$, Paul G. Bannon ${ }^{1,2,3,4}$, Martin Misfeld ${ }^{3,4,5}$, Tristan D. Yan ${ }^{2,3,6}$, \\ Giuseppe Santarpino $^{7,8,9}$, Paolo Berretta ${ }^{10}$, Marco Di Eusanio ${ }^{10}$, Bart Meuris ${ }^{11}$, Alfredo Giuseppe Cerillo ${ }^{12}$, \\ Pierluigi Stefano $^{12,13}$, Niccolò Marchionni ${ }^{13,14}$, Jacqueline K. Olive ${ }^{15}$, Tom C. Nguyen ${ }^{16,17}$, Marco Solinas $^{18}$, \\ Giacomo Bianchi ${ }^{18}$ \\ ${ }^{1}$ Sydney Medical School, The University of Sydney, Sydney, Australia; ${ }^{2}$ The Baird Institute of Applied Heart and Lung Surgical Research, Sydney, \\ Australia; ${ }^{3}$ Cardiothoracic Surgical Unit, ${ }^{4}$ Institute of Academic Surgery, Royal Prince Alfred Hospital, Sydney, Australia; ${ }^{5}$ University Department for \\ Cardiac Surgery, Leipzig Heart Center, Leipzig, Germany; ${ }^{6}$ Sydney Adventist Hospital, Sydney, Australia; ${ }^{7}$ Department of Cardiac Surgery, Anthea \\ Hospital, GVM Care \& Research, Bari, Italy; ${ }^{8}$ Department of Cardiac Surgery, Paracelsus Medical University, Nuremberg, Germany; ${ }^{9}$ Department \\ of Clinical and Experimental Medicine, Magna Graecia University, Catanzaro, Italy; ${ }^{10}$ Cardiac Surgery Unit, Lancisi Cardiovascular Center, \\ Polytechnic University of Marche, Ancona, Italy; ${ }^{11}$ Department of Cardiac Surgery, University Hospitals Leuven, Leuven, Belgium; ${ }^{12}$ Unit of Cardiac \\ Surgery, Careggi University Hospital, Florence, Italy; ${ }^{13}$ University of Florence School of Medicine, Florence, Italy; ${ }^{14}$ Unit of Cardiology, Careggi \\ University Hospital, Florence, Italy; ${ }^{15}$ Baylor College of Medicine, Houston, Texas, USA; ${ }^{16}$ Department of Cardiothoracic and Vascular Surgery, \\ University of Texas Health Science Center Houston, McGovern Medical School, Houston, Texas, USA; ${ }^{17}$ Memorial Hermann Heart and Vascular \\ Institute, Houston, Texas, USA; ${ }^{18}$ Ospedale del Cuore Fondazione Toscana “G. Monasterio", Massa, Italy \\ Correspondence to: Kei Woldendorp. 10/118 Alison Rd, Randwick, NSW 2031, Australia. Email: kei.woldendorp@gmail.com.
}

Background: New technologies such as sutureless or rapid deployment prosthetic valves and access via minimally invasive incisions offer alternatives to traditional full-sternotomy aortic valve replacement (SAVR). However, a comprehensive comparison of these surgical techniques along with alternative valve prosthesis has not been completed.

Methods: Electronic databases were searched for studies comparing outcomes for SAVR, minimally invasive AVR (MiAVR), sutureless/rapid-deployment AVR (SuAVR) via full-sternotomy, or minimally invasive SuAVR (MiSuAVR) from their inception until September 2018. Early postoperative outcomes and follow-up data were included in a Bayesian network meta-analysis.

Results: Twenty-three studies with 8,718 patients were identified. Compared with standard SAVR, SuAVR had significantly lower incidence of postoperative AF [odds ratio (OR) 0.33, 95\% confidence interval (CI): 0.14-0.79, $\mathrm{P}=0.013]$ and MiSuAVR greater requirement for postoperative permanent pacemaker (OR 2.27, 95\% CI: 1.25-4.14, $\mathrm{P}=0.008)$. All sutureless/rapid-deployment procedures had reduced cardiopulmonary bypass and cross-clamp times, by a mean of 25.9 and $25.0 \mathrm{~min}$, respectively. Hospital length of stay (LOS), but not intensive care LOS, was reduced for all groups (MiAVR -1.53 days, MiSuAVR -2.79 days, and SuAVR 3.37 days). A signal towards reduced early mortality, wound infections, and acute kidney injury was noted in both sutureless/rapid-deployment and minimally invasive techniques but did not achieve significance. Sutureless/rapid-deployment procedures had favourable survival and freedom from valve related reoperation, however follow-up times were short and demonstrated significant heterogeneity between intervention groups.

Conclusions: Minimally invasive and sutureless techniques demonstrate equivalent early postoperative outcomes to SAVR and may reduce ventilation time, hospital LOS and postoperative atrial fibrillation (POAF) burden.

Keywords: Aortic valve replacement; minimally invasive; sutureless; rapid deployment; aortic stenosis (AS); hemisternotomy; right anterior thoracotomy 
Submitted Feb 16, 2020. Accepted for publication May 05, 2020.

doi: 10.21037/acs-2020-surd-17

View this article at: http://dx.doi.org/10.21037/acs-2020-surd-17

\section{Introduction}

Aortic stenosis (AS) remains one of the most common valvular pathologies in both the developing and Western worlds. Without intervention AS progresses inexorably and once symptoms develop the life expectancy is reduced to three years on average unless the mechanical obstruction is relieved (1).

While surgical aortic valve replacement via fullsternotomy (SAVR) has for decades been the gold standard treatment for patients with severe AS, it confers additional risks to high-risk patients, particularly for those with prior cardiac surgery, renal failure, or advanced age $(2,3)$. Minimally invasive AVR (MiAVR) (via either an upper hemisternotomy or right anterior thoracotomy) was initially utilized primarily in low-risk surgical candidates but has more recently demonstrated excellent outcomes in higher risk cohorts $(4,5)$. These newer surgical approaches often lead to longer operation, bypass, and cross-clamp (CC) times which may expose patients to higher postoperative risk $(6,7)$. Sutureless and rapid deployment valve technology has more recently been developed for SAVR patients to reduce operation times and therefore complications associated with cardiopulmonary bypass (CBP) and cardioplegic arrest (8-11). Subsequently, these valves have also demonstrated excellent hemodynamic profiles when compared with traditional stented valves (12-14). While many patients and the medical community alike have expectations that minimally invasive and sutureless technology will continue to expand, limited long term data is available.

With increasing options available to surgeons, the ideal choice of approach and prosthesis has become more complex. Patient factors such as age, frailty, comorbidities and unfavourable vascular anatomy may complicate the decision for minimally invasive procedures but for the large majority of surgical candidates it is left up to individual surgeon discretion. Many individual institutions have compared either rapid deployment or minimally invasive approaches to SAVR, however no single study has yet attempted to consolidate these reports and analyze the collated short and long-term outcomes.

Here we have performed a Bayesian network metaanalysis to compare short- and long-term outcomes following SAVR, MiAVR, sutureless AVR (SuAVR) via fullsternotomy, or minimally invasive SuAVR (MiSuAVR) in the setting of severe AS.

\section{Methods}

\section{Search strategy and study selection}

Electronic searches were performed using Medline, Cochrane central register of controlled trials, Web of Knowledge and PubMed, according to the PRIMSA statement of the conduct of systematic reviews and meta-analysis (15). The terms "aortic valve", "aortic valve replacement", or "SAVR" were combined with "minimally invasive", "mini", "hemi sternotomy", "right thoracotomy", "sutureless", or "rapid deployment prosthesis" as both keywords and MeSH terms. Two reviewers (KW and MD) independently screened the title and abstract of records identified in the search. Full-text publications were subsequently reviewed separately if either reviewer considered the manuscript as potentially eligible for inclusion. The reference list of all retrieved articles was reviewed for further identification of potentially relevant studies (Table S1). Only studies published in English were included.

\section{Inclusion criteria}

Eligible studies were those comparing separate cohorts of patients undergoing isolated aortic valve replacement via either sternotomy or a minimally invasive surgical approach (RAT or HS), using either conventional stented bioprosthesis or a sutureless/rapid deployment bioprosthesis, and reported on short- and/or long-term outcomes. Where multiple studies reported on the same patient cohort, only the most recent publication was included.

\section{Study endpoints}

Primary endpoints were early (30-day) mortality and stroke. Secondary endpoints were new postoperative atrial fibrillation (POAF), acute kidney injury (AKI), need for permanent pacemaker (PPM), major bleeding, sternal infections, intensive care unit (ICU), length of stay 
(LOS), overall hospital LOS, late mortality, and need for reoperation for valve dysfunction.

\section{Analysis}

Pooled values were reported as mean \pm standard deviation or as otherwise specified. Data transformation was completed using established statistical methods when studies presented it as either median and range (16), or median and interquartile range (IQR) $(17,18)$. Data were summarized as standard mean difference, with overall weighted mean presented where appropriate. $\mathrm{I}^{2}$ statistic was used to estimate the percentage of total variation across studies, due to heterogeneity rather than chance. An $\mathrm{I}^{2}$ value of greater than $50 \%$ was considered substantial heterogeneity. If there was substantial heterogeneity, the possible clinical and methodological reasons for this were explored qualitatively. All $\mathrm{P}$ values were 2 -sided. A significant difference was defined as $\mathrm{P}<0.05$.

Statistical analysis was conducted with STATA Version 16 (StataCorp. 2019. Stata Statistical Software: College Station, TX: StataCorp LLC) using a program mometa to perform Bayesian network meta-analyses using Markov chain Monte Carlo stimulation as described by White (19). The number of burn-in runs was set at 10,000 for assessing the convergence of parameter estimates. The odds ratio was used as the summary statistic with $95 \%$ confidence intervals as the measure of uncertainty. Random effects modelling was used to account for heterogeneity across studies that was not accounted for by the $\mathrm{I}^{2}$ statistic such as different surgeons, anaesthetists, and intensive care and high dependency care protocols. Mvmeta generates a network diagram that allows visual assessment of the connections between the different intervention groups and which are directly or indirectly connected. The size of the nodes is correlated with the sample size of each intervention group and the thickness of the edges relates to the number of comparative studies between two interventions. For each analysis a forest plot is produced with random effects modelling examining both within and between study effects. The Rankogram is a visual representation of the SUCRA score (a measure-surface under the cumulative ranking curve-that utilises both the forest plot and league table data). The SUCRA percentage gives the probability of an interventions ranking as best for the particular variable examined, and uses probability derived from the posterior distribution of all treatments $(19,20)$ (Table S2).

\section{Results}

A total of 1,437 publications were identified through the database and bibliographic searches. After exclusion of duplicated or irrelevant publications, a total of 23 relevant articles were included and reviewed in detail (Table S1). A total of 8,718 patients were identified across 23 patient series. There were 4,717 patients who had a full-sternotomy AVR receiving either a stented prosthesis (4,421 patients) or sutureless/rapid-deployment prosthesis (296 patients). A minimally invasive approach to AVR was performed in 4,088 patients, with 2,985 patients receiving a stented prosthesis and 1,016 patients a sutureless/rapid-deployment prosthesis. Within the minimally invasive group, 1,924 patients had a hemi-sternotomy (HS) and 1,665 patients had a right anterior thoracotomy (RAT), the rest were undefined.

\section{Baseline characteristics}

\section{Pooled data}

Mean age of patients having a full sternotomy was $70.4 \pm 11.4$ years, while the mean age of patients undergoing a minimally invasive procedure was $70.9 \pm 11.8$ years. Of the 8608 patients where sex was recorded, $42.7 \%$ were female. Patients undergoing full-sternotomy procedures were less likely to be female $(41.0 \%$ vs. $44.6 \%, \mathrm{P}<0.001)$, marginally but statistically significantly younger $(70.4 \pm 11.4$ vs. $70.9 \pm 11.8$ years, $\mathrm{P}<0.044$ ), and significantly more likely to have New York Heart Association (NYHA) Class III/ IV symptoms $[52.1 \%(877 / 1,677)$ vs. $43.6 \%(724 / 1,661)$, $\mathrm{P}<0.0001]$ compared to minimally invasive procedures. Left ventricular ejection fraction (LVEF) was similar between the two groups $\{59.0 \% \pm 10.4 \%[2,433]$ vs. $59.1 \% \pm 8.8 \%$ $[3,460], \mathrm{P}<0.69\}$.

Data for the type of rapid deployment valve was present in $87 \%$ of the studies examined. Overall, the Livanova Perceval valve was used most commonly (84.3\% of cases), followed by the Edwards Intuity (9.9\%) and finally the Medtronic 3F Enable (5.8\%). Although the 3F Enable valve is no longer marketed we included it in this analysis due to the heterogenous inclusion within other studies.

Further demographic details on subgroup by type of prosthesis is shown in Table 1 .

\section{Outcomes analysis}

After exclusion of non-matched studies, 6,553 patients from 23 studies were included in a Bayesian network meta-analysis of propensity-matched, postoperative outcomes (Table 2). 


\begin{tabular}{|c|c|c|c|c|c|c|c|c|c|c|}
\hline \multirow{2}{*}{ Characteristics } & \multirow{2}{*}{ I. SAVR } & \multirow{2}{*}{ II. MiAVR } & \multirow{2}{*}{ III. SuAVR } & \multirow{2}{*}{ IV. MiSuAVR } & \multicolumn{6}{|l|}{$P$ value } \\
\hline & & & & & | vs. || & | vs. III & I vs. IV & II vs. III & II vs. IV & III vs. IV \\
\hline $\mathrm{n}$ & 4,421 & 2,985 & 296 & 1,016 & & & & & & \\
\hline Age (yrs) & 69.7 & 69.1 & 75 & 76.8 & 0.97 & $<0.001$ & $<0.001$ & $<0.001$ & $<0.001$ & $<0.001$ \\
\hline LVEF (\%) & 59 & 59.2 & 56.5 & 58.8 & 0.41 & 0.05 & 0.7 & 0.03 & 0.16 & 0.07 \\
\hline Female (\%) & 40.9 & 40.5 & 59.1 & 57.6 & $<0.001$ & $<0.001$ & $<0.001$ & 0.005 & $<0.001$ & 0.64 \\
\hline Previous stroke (\%) & 7.4 & 5.6 & 16.9 & 2.9 & 0.005 & $<0.001$ & $<0.001$ & $<0.001$ & 0.02 & $<0.001$ \\
\hline Peripheral vascular disease (\%) & 10.0 & 10.6 & 16.1 & 14.9 & $<0.001$ & 0.96 & $<0.001$ & 0.12 & 0.12 & 0.006 \\
\hline Diabetes (\%) & 21.1 & 20.4 & 25.4 & 27.5 & 0.03 & 0.01 & $<0.001$ & $<0.001$ & $<0.001$ & 0.34 \\
\hline Hypertension (\%) & 66.3 & 70.6 & 76.3 & 88.0 & $<0.001$ & $<0.001$ & $<0.001$ & $<0.001$ & $<0.001$ & $<0.001$ \\
\hline COPD (\%) & 12.6 & 12.0 & 21.4 & 11.6 & 0.003 & $<0.001$ & 0.01 & $<0.001$ & $<0.001$ & $<0.001$ \\
\hline Atrial fibrillation (\%) & 11.3 & 8.6 & 20.1 & 15.3 & 0.45 & $<0.001$ & $<0.001$ & $<0.001$ & $<0.001$ & 0.26 \\
\hline Renal failure (\%) & 6.1 & 2.9 & 1.0 & 19.6 & $<0.001$ & 0.002 & $<0.001$ & 0.2 & $<0.001$ & $<0.001$ \\
\hline
\end{tabular}

COPD, chronic obstructive pulmonary disease; LVEF, left ventricular ejection fraction; SAVR, full sternotomy aortic valve replacement; SuAVR, sutureless aortic valve replacement via full sternotomy; MiAVR, minimally invasive aortic valve replacement; MiSuAVR, sutureless aortic valve replacement via minimally invasive procedure.

Table 2 Baseline patient characteristics for network meta-analysis (pooled from matched data)

\begin{tabular}{|c|c|c|c|c|c|c|c|c|c|c|}
\hline Characteristics & I. SAVR & II. MiAVR & III. SuAVR & IV. MiSuAVR & \multicolumn{6}{|c|}{$P$ value } \\
\hline$n$ & 2,862 & 2,545 & 274 & 872 & & & & & & \\
\hline Age (yrs) & 70.2 & 69.3 & 74.6 & 75.9 & 0.57 & 0.07 & 0.04 & 0.03 & 0.001 & 0.25 \\
\hline LVEF (\%) & 57.2 & 57.5 & 56.6 & 58.6 & 0.92 & 0.83 & 0.66 & 0.70 & 0.73 & 0.38 \\
\hline Previous stroke (\%) & 7.3 & 4.8 & 13.8 & 3.8 & 0.21 & 0.35 & 0.53 & 0.26 & 0.55 & 0.06 \\
\hline Peripheral vascular disease (\%) & 8.3 & 8.7 & 8.6 & 14.1 & 0.85 & 0.96 & 0.04 & 0.98 & 0.07 & 0.40 \\
\hline Diabetes (\%) & 19.8 & 18.9 & 24.8 & 33.1 & 0.81 & 0.19 & 0.03 & 0.16 & 0.007 & 0.07 \\
\hline Hypertension (\%) & 66.6 & 68.7 & 76.2 & 78.4 & 0.78 & 0.14 & 0.09 & 0.09 & 0.05 & 0.34 \\
\hline Renal failure (\%) & 5.8 & 4.0 & 1.1 & 9.5 & 0.30 & 0.17 & 0.29 & 0.08 & 0.12 & 0.03 \\
\hline
\end{tabular}

All data is expressed as proportions rather than absolute numbers. COPD, chronic obstructive pulmonary disease; LVEF, left ventricular ejection fraction; SAVR, full sternotomy aortic valve replacement; SuAVR, sutureless aortic valve replacement via full sternotomy; MiAVR, minimally invasive aortic valve replacement; MiSuAVR, sutureless aortic valve replacement via minimally invasive procedure. 


\begin{tabular}{|c|c|c|c|c|}
\hline Mortality (30-day) & $2.8 \%(54 / 1,940)$ & $3.7 \%(5 / 135)$ & $1.8 \%(32 / 1,818)$ & $1.7 \%(9 / 529)$ \\
\hline Stroke & $2.1 \%(32 / 1,508)$ & $1.0 \%(1 / 97)$ & $1.8 \%(26 / 1,459)$ & $2.9 \%(14 / 488)$ \\
\hline Bleeding (major) & $3.5 \%(63 / 1,825)$ & $5.3 \%(5 / 94)$ & $3.7 \%(65 / 1,748)$ & $6.2 \%(33 / 529)$ \\
\hline New postoperative AF & $27.9 \%(340 / 1,221)$ & NA & $21.2 \%(296 / 1,395)$ & $15.6 \%(40 / 256)$ \\
\hline Acute kidney injury & $3.1 \%(66 / 2,129)$ & $4.6 \%(9 / 195)$ & $1.6 \%(23 / 1,455)$ & $1.1 \%(5 / 453)$ \\
\hline Surgical site infection & $2.5 \%(11 / 447)$ & $0.0 \%(0 / 56)$ & $2.4 \%(13 / 532)$ & $3.0 \%(7 / 235)$ \\
\hline CPB time (min) & $102.3 \pm 59.9$ & $77.7 \pm 58.3$ & $108.4 \pm 39.3$ & $80.9 \pm 23.9$ \\
\hline Intensive care unit LOS (days) & $1.9 \pm 1.8$ & $3.3 \pm 3.8$ & $1.9 \pm 2.4$ & $1.4 \pm 1.3$ \\
\hline Hospital LOS (days) & $8.1 \pm 5.1$ & $12.8 \pm 6.7$ & $7.3 \pm 5.2$ & $6.9 \pm 4.2$ \\
\hline
\end{tabular}

\section{Operative details}

Compared with stented valve procedures, all procedures using sutureless/rapid-deployment prosthesis had significantly shorter CBP and CC times, while choice of surgical access appeared to have no effect on overall CPB or CC times (Tables 3,4 and Figures S1,S2). When comparing all procedures simultaneously SuAVR followed by MiSuAVR were ranked as most superior in terms of $\mathrm{CPB}$ and CC times.

\section{Postoperative outcomes}

Network meta-analysis demonstrated no significant difference in early mortality, stroke, major bleeding, AKI, surgical site complications and ICU stay between the different surgical groups. Bayesian Markov chain Monte Carlo modelling demonstrated that SuAVR had the most favorable outcomes of all AVR techniques, other than for cerebrovascular events (Figures S1,S2).

Postoperative AF was less frequent after minimally invasive surgery with either a sutureless/rapid-deployment or stented prosthesis (15.6\% and $21.2 \%$, respectively) compared to conventional full sternotomy stented AVR (27.9\%). While the incidence of new complete heart block or bradyarrhythmia requiring pacemaker insertion was significantly higher for sutureless/rapid-deployment valves (3.6\% and 7.7\%; SuAVR and MiSuAVR respectively) compared to stented valves $(2.7 \%$ and $2.8 \%$; AVR and MiAVR respectively). However, there was no significant difference between surgical approach within each group.

Postoperative ventilation time trended lower for all procedures compared with SAVR, however only the sutureless/ rapid-deployment alternatives demonstrated a significant difference (SuAVR $-2.5 \mathrm{hrs}$ and MiSuAVR $-3.4 \mathrm{hrs}$ ). Similarly, hospital LOS was significantly shorter for all surgical groups other that SAVR, however inconsistency modelling demonstrated significant heterogeneity within study groups.

Further information about peri-procedural outcomes is detailed in Tables 3,4 and Figures 1-3.

\section{Follow-up}

\section{Late mortality}

Data on mortality greater than one year following surgery was available for 1,859 patients, of which 384 had a full sternotomy (328 stented, 56 sutureless/rapid-deployment) with a mean follow-up time of 45.6 months, and 1,485 had a minimally invasive procedure (703 stented, 782 sutureless/rapiddeployment) with a mean follow-up time of 29.1 months. 


\begin{tabular}{|c|c|c|c|c|}
\hline Variable & MiAVR & MiSuAVR & SuAVR & Test for inconsistency \\
\hline Mortality & $0.73(0.46-1.13), P=0.16$ & $0.64(0.3-1.38), P=0.25$ & $1.49(0.28-1.62), P=0.37$ & $P=0.41$ \\
\hline Stroke & $0.78(0.49-1.25), P=0.30$ & 1.05 (0.51-2.18), $P=0.89$ & 1.4 (0.52-3.86), $P=0.50$ & $P=0.50$ \\
\hline Bleeding & $1.17(0.79-1.77), P=0.42$ & $1.22(0.67-2.23), P=0.52$ & $0.59(0.22-1.57), P=0.29$ & $P=0.18$ \\
\hline AKI & 0.98 (0.42-2.27), $\mathrm{P}=0.96$ & 1.01 (0.36-2.86), $P=0.98$ & $0.82(0.22-2.97), P=0.76$ & $P=0.45$ \\
\hline POAF & $0.82(0.58-1.15), P=0.25$ & $0.61(0.32-1.15), P=0.13$ & $0.33(0.14-0.79), P=0.013$ & - \\
\hline PPM & 1.05 (0.63-1.75), $\mathrm{P}=0.86$ & 2.27 (1.25-4.14), $P=0.008$ & 0.70 (0.12-4.06), $P=0.69$ & - \\
\hline Infection & $0.62(0.29-1.34), P=0.22$ & $0.56(0.18-1.8), P=0.33$ & $0.63(0.13-3.00), P=0.56$ & $P=0.97$ \\
\hline CPB (min) & $6.7(-2.0-15.5), P=0.13$ & $-24.2(-35.1--13.4), P<0.001$ & $-27.6(-41.8--13.3), P<0.001$ & $P=0.67$ \\
\hline X-clamp (min) & $5.2(-1.1-11.5), P=0.11$ & $-23.9(-31.8--16.0), P<0.001$ & $-26.1(-36.1--16.1), P<0.001$ & $P=0.96$ \\
\hline Vent (hrs) & $-0.91(-2.06-0.23), P=0.12$ & $-3.43(-5.47--1.38), P=0.001$ & $-2.49(-5.14-0.17), P=0.07$ & - \\
\hline ICU LOS (days) & $-0.10(-0.45-0.26), P=0.60$ & $-0.27(-0.80-0.27), P=0.33$ & $-0.35(-1.30-0.59), P=0.46$ & $P=0.38$ \\
\hline Hospital LOS (days) & $-1.53(-2.85--0.21), P=0.02$ & $-2.79(-4.81--0.78), P=0.007$ & $-3.37(-5.81--0.94), P=0.007$ & $P=0.04$ \\
\hline
\end{tabular}

Results are shown as odds ratio ( $95 \%$ confidence interval) for dichotomous variables and mean difference (95\% Cl) for continuous variables. AKI, acute kidney injury; X-clamp, cross-clamp time; CPB, cardiopulmonary bypass time; ICU, intensive care unit; LOS, length of stay; MiAVR, minimally invasive aortic valve replacement; MiSuAVR, sutureless aortic valve replacement via minimally invasive procedure; POAF, postoperative atrial fibrillation; PPM, permanent pacemaker; SuAVR, sutureless aortic valve replacement via full sternotomy; Vent, ventilation time.

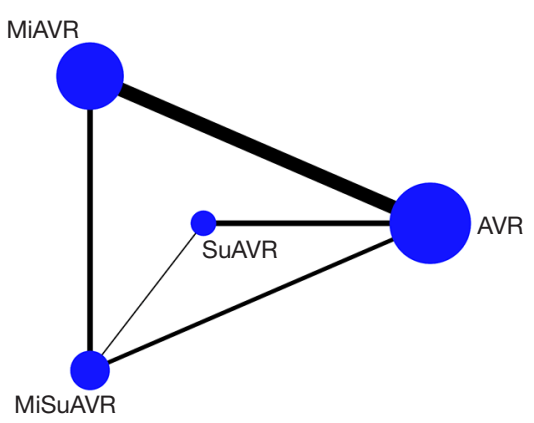

Figure 1 Network map for AVR by surgical approach and prosthesis examining postoperative outcomes. AVR, full sternotomy aortic valve replacement; MiAVR, minimally invasive AVR; SuAVR, sutureless AVR; MiSuAVR, minimally invasive sutureless AVR.

There were 49 late deaths $(12.8 \%)$ in the full-sternotomy group and $67(4.5 \%)$ in the minimally invasive cohort. When comparing late mortality in the network metaanalysis MiSuAVR demonstrated superiority, however there was significant heterogeneity (OR 0.26, 95\% CI: 0.13-0.54, $\mathrm{P}<0.001)$.

\section{Reoperation for valve dysfunction}

Only four studies reported outcomes for reoperation. These studies compared sutureless versus stented valves in minimally invasive procedures (MiSuAVR $v s$. MiAVR), over a mean follow-up time of $27.5 \pm 19.0$ months (MiSuAVR $13.3 \pm 14.1$ months, MiAVR 42.0 \pm 17.2 months). There were 15 reoperations $(2.7 \%)$ in patients who had a stented prosthesis via minimal access surgery and 5 reoperations $(0.9 \%)$ in those with a sutureless/rapid-deployment prosthesis. Bayesian network meta-analysis demonstrated that sutureless prosthesis had lower overall reoperation, however there was only borderline statistical significance, and significant heterogeneity (OR 0.27, 95\% CI: 0.07-1.00, $\mathrm{P}=0.05)$ (Tables 5,6 and Figure 4).

\section{Discussion}

The results of our network meta-analysis on propensitymatched patients show that there is no significant difference in early mortality, stroke, major bleeding, AKI, and surgical site infection for minimally invasive and sutureless/rapid-deployment aortic valve prosthesis compared to traditional full-SAVR. While patients who 
Mortality

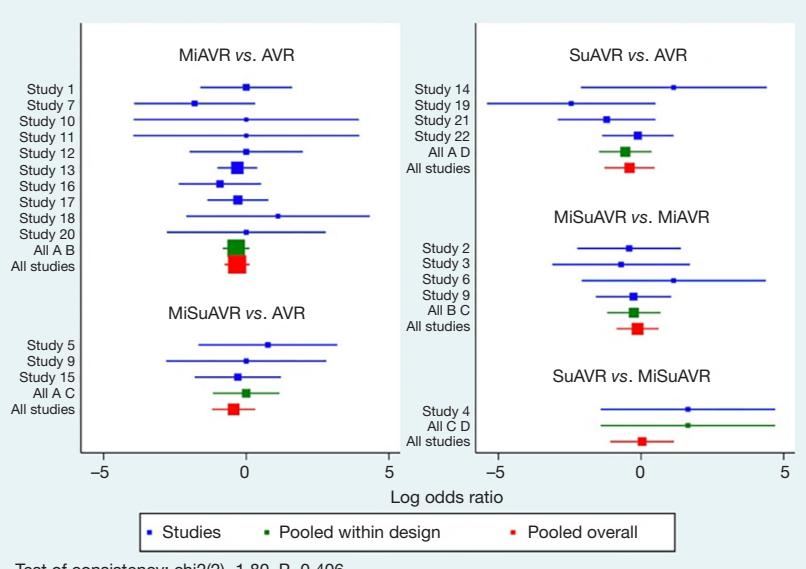

Test of consistency: $\operatorname{chi} 2(2)=1.80, P=0.406$

Postoperative AF

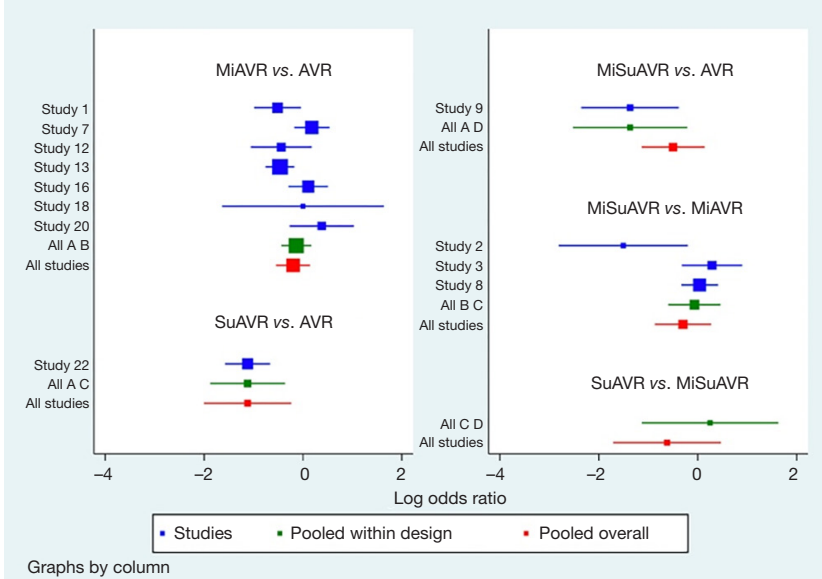

Ventilation (hours)

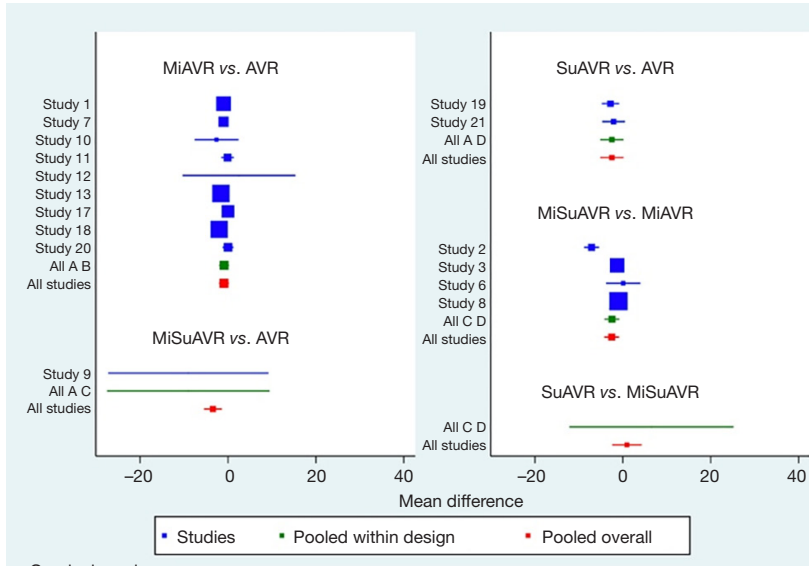

Graphs by column

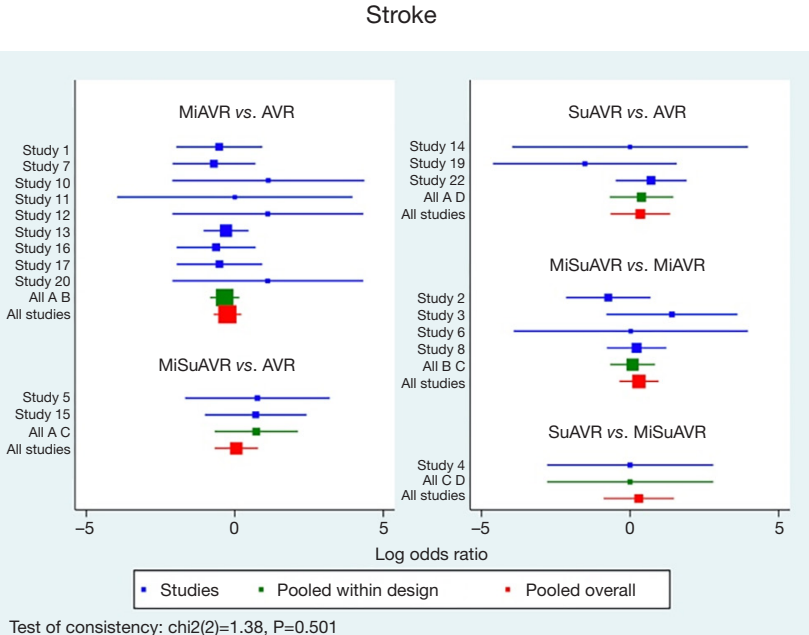

Pacemaker Requirement

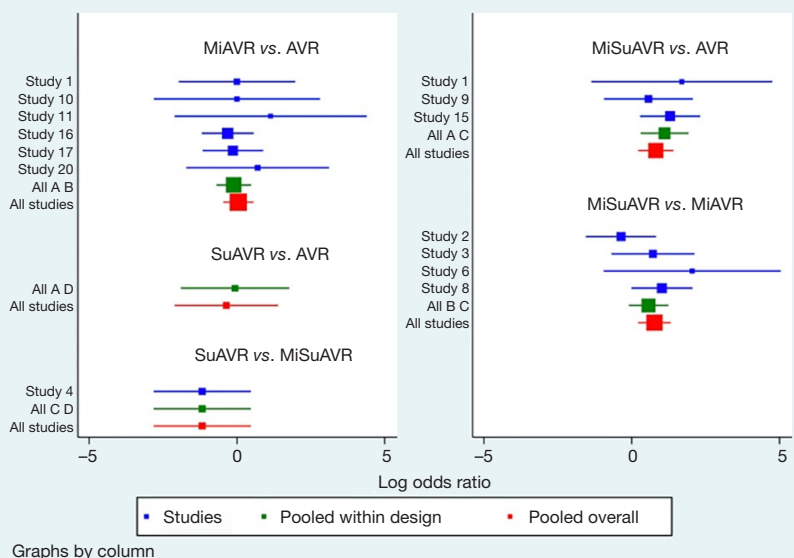

Hospital Stay (days)

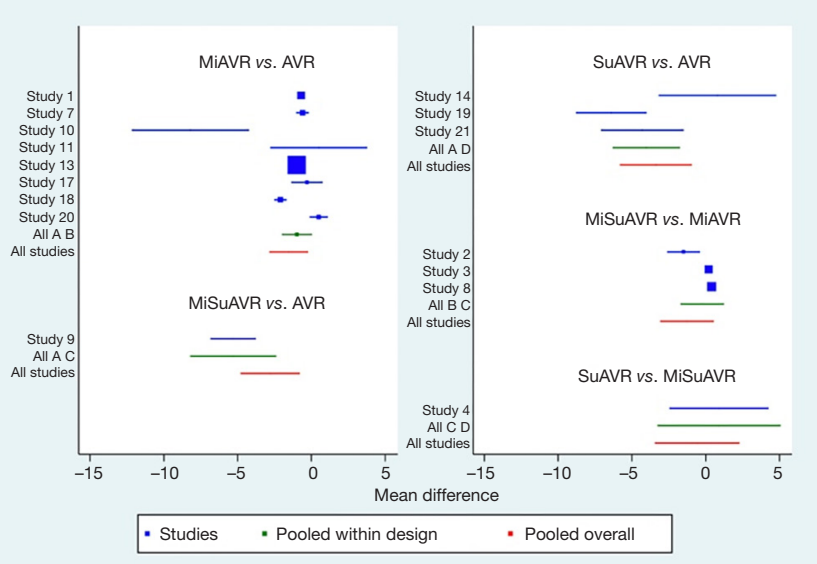

Test of consistency: $\operatorname{chi2}(2)=6.38, P=0.041$

Figure 2 Forest plots for AVR by surgical approach and prosthesis examining postoperative outcomes. AVR, full sternotomy aortic valve replacement; MiAVR, minimally invasive AVR; SuAVR, sutureless AVR; MiSuAVR, minimally invasive sutureless AVR. 
Mortality

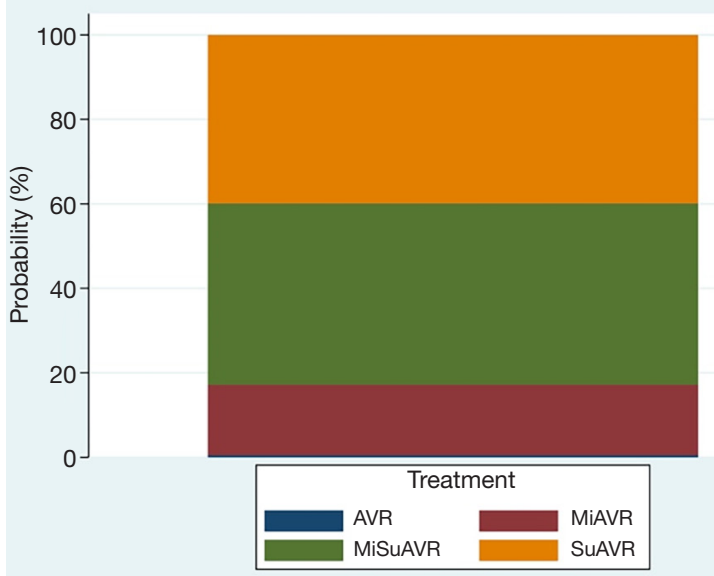

Postoperative AF

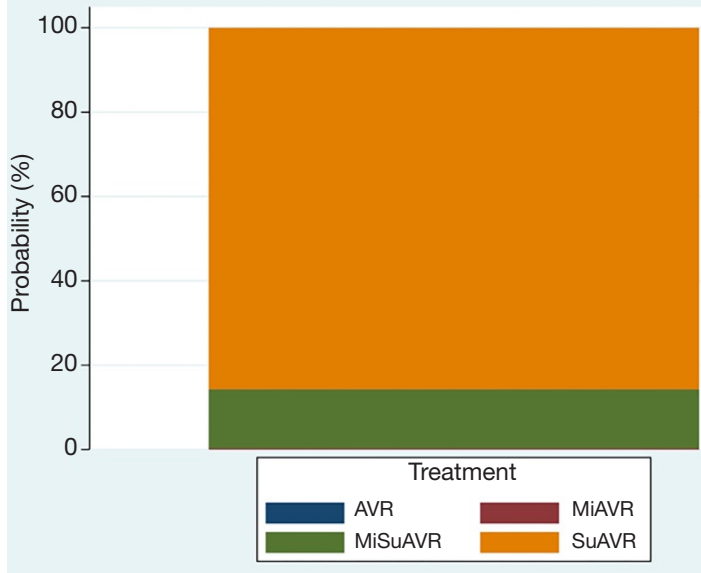

Ventilation (hours)

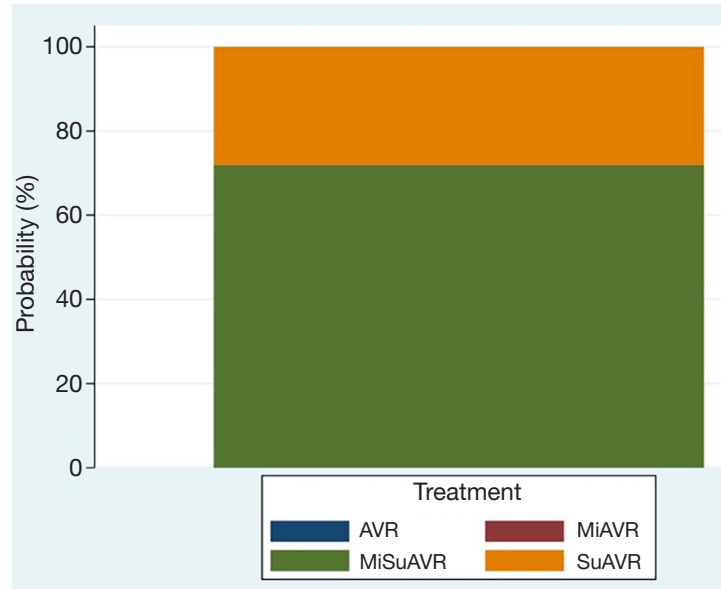

Stroke

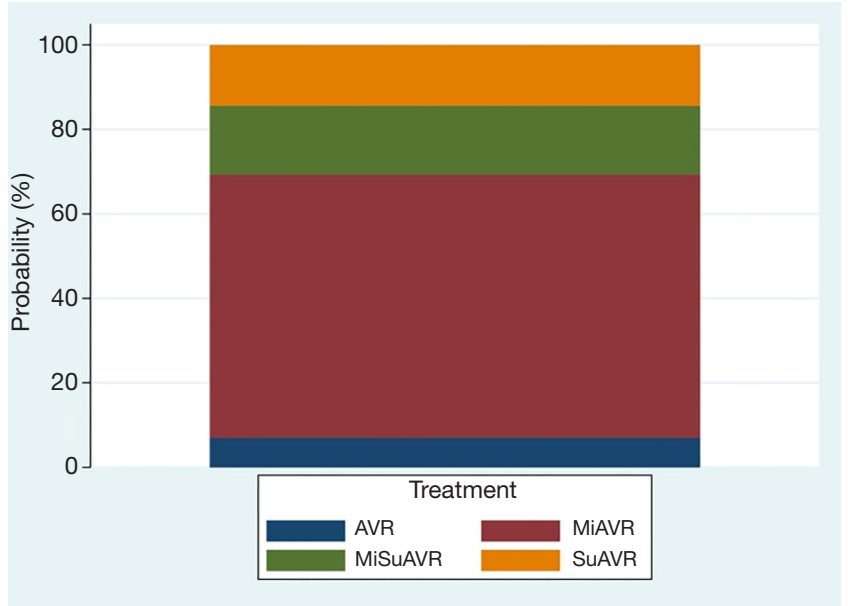

Pacemaker Requirement

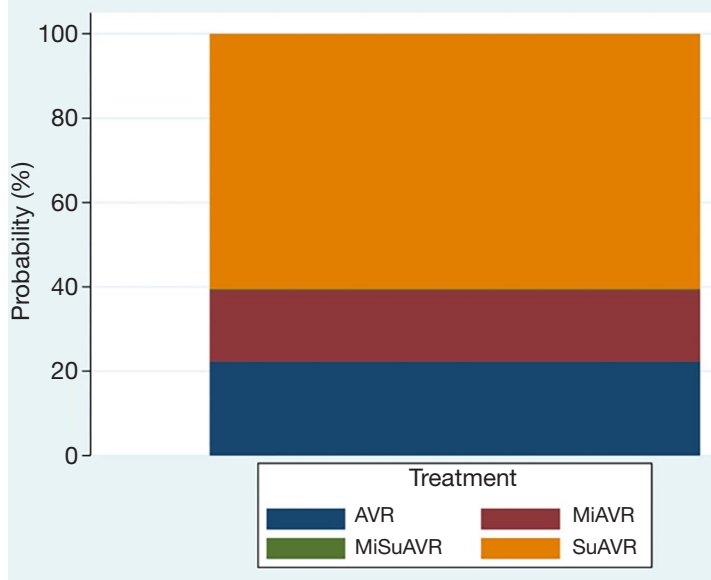

Hospital Stay (days)

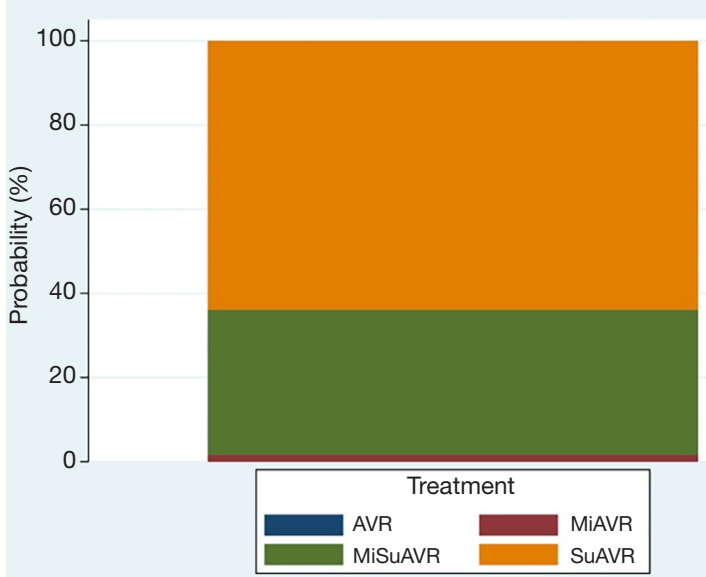

Figure 3 Rankograms for AVR by surgical approach and prosthesis examining postoperative outcomes. For example, if suAVR accounts for $40 \%$ of the rankogram, then it has a $40 \%$ probability of being the best-ranked treatment option for that particular outcome. AVR, full sternotomy aortic valve replacement; MiAVR, minimally invasive AVR; SuAVR, sutureless AVR; MiSuAVR, minimally invasive sutureless AVR. 


\begin{tabular}{lllll}
\hline Table 5 Patient outcomes at follow-up & \multicolumn{1}{l}{} \\
\hline Variable & SAVR & SuAVR & MiAVR & MiSuAVR \\
\hline Follow-up (months) & $51.3 \pm 19.3$ & $16.7 \pm 20.9$ & $44.9 \pm 17.1$ & $13.3 \pm 11.5$ \\
\hline Mortality (late) (n) & $13.4 \%(44 / 328)$ & $8.9 \%(5 / 56)$ & $5.4 \%(38 / 703)$ & $3.7 \%(29 / 782)$ \\
Valve related reoperation & NA & NA & $2.7 \%(15 / 546)$ & $0.9 \%(5 / 555)$ \\
$\quad$ Structural valve deteriorate & & & $0.9 \%(5 / 546)$ & 0 \\
\multicolumn{1}{l}{ Infective endocarditis } & & & $0.9 \%(5 / 546)$ & $0.4 \%(2 / 555)$ \\
\multicolumn{1}{l}{ Unknown } & & & $0.9 \%(5 / 546)$ & $0.5 \%(3 / 555)$ \\
\hline
\end{tabular}

SAVR, full sternotomy aortic valve replacement; SuAVR, sutureless aortic valve replacement via full sternotomy; MiAVR, minimally invasive aortic valve replacement; MiSUAVR, sutureless aortic valve replacement via minimally invasive procedure; NA, no data available.

\begin{tabular}{l}
\multicolumn{5}{l}{ Table 6 Bayesian network meta-analysis late outcomes based on a consistency model using SAVR as a baseline comparator } \\
\begin{tabular}{lllll}
\hline Variable & MiAVR & MiSuAVR & SuAVR & Test for inconsistency \\
\hline Mortality & $0.59(0.25-1.38), P=0.22$ & $0.26(0.13-0.54), P<0.001$ & $0.46(0.07-2.89), P=0.41$ & - \\
Reoperation* & $*$ & $0.27(0.07-1.00), P=0.05$ & - & - \\
\hline Results are shown as odds ratio (95\% confidence interval). * Reoperation used MiAVR as the baseline comparator.
\end{tabular}
\end{tabular}

receive sutureless/rapid-deployment prosthesis have significantly shorter CBP and CC times. Although the $3 \mathrm{~F}$ Enable valve is no longer marketed, it was used in only $5.8 \%$ of all procedures in this analysis, and its inclusion would be unlikely to alter the findings reported here. These results are important for the modern cardiac surgeon as there is increasing demand from patients and the medical community for minimally invasive surgical approaches, particularly as these have demonstrated reductions in pain and cosmesis (21-23), while still being able to provide the same peri-operative and short term results of SAVR (24-27). As treatment options increase along with patient complexity, the incorporation of a heart team into the decision making model regarding patients' suitability for surgery will help identify the most appropriate procedure on a case-by-case basis (28).

Although our analysis demonstrated no significant difference in sternal wound complications, ranked modelling (based on the probability of the posterior distribution) suggested that minimally invasive and sutureless/rapiddeployment procedures were favored compared to traditional SAVR. Deep sternal wound infection remains a significant contributor to overall morbidity and mortality after cardiac surgery. Strategies to reduce surgical site infection may include reductions, CBP times and soft tissue handling (29-32) which are inherent to minimally invasive and sutureless/rapid-deployment techniques. Furthermore, the use of a right anterior thoracotomy approach for SAVR, as was used in a third of the patients included in this analysis, significantly alters the profile of postoperative wound infection.

The incidence of new complete heart block or requirement for PPM was $2.8 \%$ and $7.7 \%$ for minimal access procedures (stented and sutureless/rapid-deployment, respectively), and $2.7 \%$ and $3.6 \%$ for full sternotomy procedures (stented and sutureless/rapid-deployment, respectively. This higher incidence of PPM requirement after sutureless/rapid-deployment valves is in keeping with the published literature with of PPM rates after stented AVR that are considerably lower (2.0-3.6\%) than those using sutureless/rapid-deployment prosthesis (2.3\% to $17 \%$ ) including studies examining matched high-risk patients to TAVI (12,33-36). Large registry data has demonstrated increased all-cause long-term mortality in patients requiring PPM after SAVR and this decreased survival is also apparent in non-surgical valve replacement groups such as TAVI patients (37) thus highlighting the importance of this postoperative issue. It is worthwhile noting that recently there have been several large publications noting far lower PPM rates after sutureless/rapid-deployment prosthesis 
Late mortality

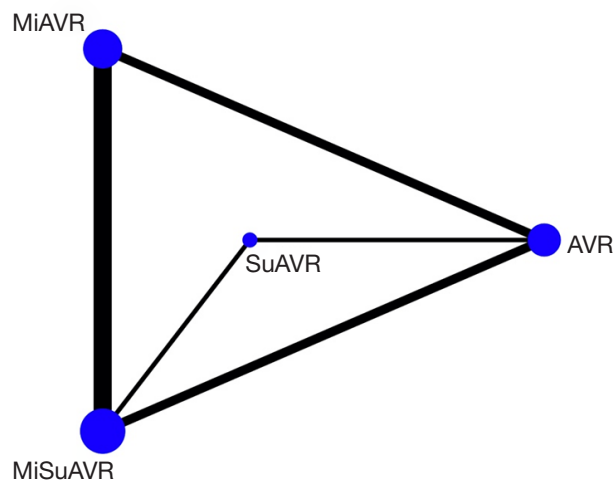

Reoperation (valve related)
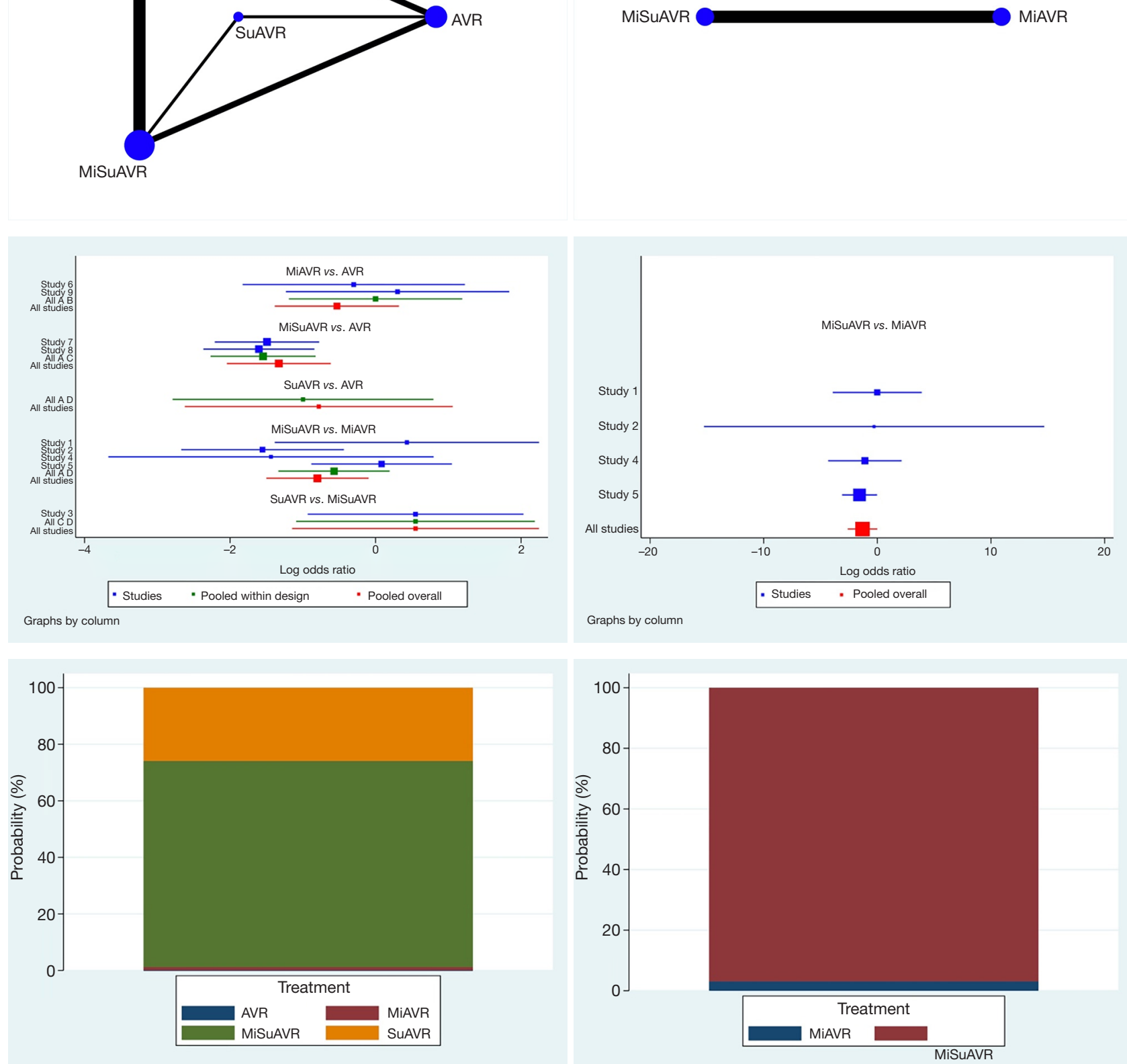

Figure 4 Network map, forest plot and rankogram for AVR by surgical approach and prosthesis examining late postoperative outcomes. For example, if suAVR accounts for $40 \%$ of the rankogram, then it has a $40 \%$ probability of being the best-ranked treatment option for that particular outcome. AVR, full sternotomy aortic valve replacement; MiAVR, minimally invasive AVR; SuAVR, sutureless AVR; MiSuAVR, minimally invasive sutureless AVR. 
$(38,39)$. This may be due to a greater focus on procedural modifications that reduce the incidence of conduction system injury or improved patient selection.

Sutureless/rapid-deployment prostheses rely on radial force, and often subannular components to retain the prosthetic valve in its deployed position. Reducing the subannular portion of the valve that is inserted by modifying the deployment height or by using an alternative prosthesis (with anatomical variants such as a short membranous septum) significantly reduces postoperative pacemaker requirement (40-42). Over $90 \%$ of the sutureless valves inserted in this analysis were of the self-expanding variety (Perceval or 3F Enable). Self-expanding prostheses have been shown to have significantly higher rates of postoperative conduction disturbance compared to balloonexpanded prostheses, and this is true for both surgical as well as the transcatheter literature $(40,43)$. Finally, avoiding the use of sutureless prostheses in patients with other nonmodifiable risk factors for postoperative pacemakers, such as older age and presence of pre-operative conduction abnormalities (particularly right bundle branch block), are further important considerations in the workup of any surgical candidate for aortic valve replacement.

Rates of postoperative AF (POAF) were significantly higher in full sternotomy AVR (27.9\%) compared to any minimally invasive procedure $(21.2 \%$ and $15.6 \%$ for stented and sutureless, respectively). The causes for POAF are multifactorial, however the systemic inflammatory response from CBP and cold ischaemia time have all been causally linked to its development in surgical AVR $(44,45)$. POAF is linked to significant increases in hospital LOS (46), and patients who do not revert to sinus rhythm have increased risk of stroke and long-term mortality. Studies examining links between CPB and CC times in MiAVR cohorts have shown trends towards lower rates of $\operatorname{POAF}(27,47)$. This trend is amplified with the use of a sutureless valve via a minimally invasive incision, which further reduces $\mathrm{CPB}$ and CC times as well as POAF rates $(5,48)$. Our analysis confirmed these trends, with all procedures utilizing sutureless bioprosthesis having significantly shorter $\mathrm{CPB}$ and CC times. The trend for worse postoperative outcomes with longer CBP times has again been demonstrated in a recent review of low-risk patients undergoing cardiac surgery (11). The reductions in CBP and CC times offer further benefits in the case of complex or multi-valve cases when operation times are expected to be long and a full sternotomy is required, or for building on benefits provided by minimally invasive surgical approaches.
The avoidance of sternotomy is important in elderly and high-risk cohorts where recovery can be significantly impaired by postoperative pain potentially leading to respiratory compromise. In our analysis, minimally invasive procedures demonstrated reduced mechanical ventilation time and overall hospital LOS compared to full sternotomy. Reduced postoperative pain and opiate analgesia requirements may contribute to decreased ventilatory support requirements $(23,48)$. A reduction in long term survival has also been associated with prolonged postoperative mechanical ventilation time (26).

Although absolute values for late mortality were higher in full sternotomy procedures compared to minimally invasive procedures (12.8\% and $4.5 \%$, respectively) there was large heterogeneity between the groups and the results should be examined with this consideration in mind. Although studies were propensity-matched there is likely a residual effect of patient selection that particularly confounds this outcome. This was similar to the results for late valve reoperation where sutureless valves (via minimal access) demonstrated lower raw rates of late valve-related reoperations $(0.9 \%$ and $2.7 \%$, respectively). Furthermore, a third of valverelated reoperations were for infective endocarditis which is unlikely to be related to prosthesis choice at the primary operation. Variability in follow-up time and in unpublished variables are other considerations that confound these late outcomes. Limited long-term data is available for sutureless valve performance and our result may provide some reassurance that new valve technologies are at least as robust as traditional valves at mid-term follow-up. Larger studies with long-term follow-up are required to accurately answer any questions regarding long-term safety and reliability of these new prostheses. With the recent expansion of transcatheter aortic valve replacement to lower risk patients the ongoing refinements of minimally invasive aortic valve surgery, and progress in device technology have improved the range of therapeutic options available to surgeons and patients alike, overcoming some of the shortcomings of aortic valve replacement via a full sternotomy.

\section{Limitations}

Limitations of this study include the retrospective nature of the included studies, meaning that selection bias cannot be excluded. Including only propensity-matched data into the analysis reduces this risk, however as the data was collected retrospectively and is based on administrative data the effect of unregistered covariates on the clinical 
outcomes cannot be accounted for. The lack of complete data on the type of sutureless or stented valve implanted also means that effect modifiers or confounding factors cannot be excluded from outcome analysis. Furthermore, as this paper relies on published case series this only reflects a small percentage of patients who develop postoperative AF, and these studies are likely from large volume or academic centres. Patient level data was not accessed for this study from each published series and this may reveal significant heterogeneity not currently evident. These issues could be addressed by accessing patient level data from each study or from registries that includes individual patient data for more detailed meta-analysis of outcomes.

\section{Conclusions}

The use of either a minimally invasive approach and/or sutureless/rapid-deployment prostheses confers equivalent very-low early mortality and stroke risk compared to AVR via full sternotomy, with a reduction in postoperative ventilation time, hospital stay and postoperative AF. When comparing all procedures SuAVR followed by MiSuAVR were associated with the greatest reductions in CBP and CC times. This reduction in perioperative morbidity requires further large, prospective trials in order to more clearly delineate which surgical approach and prosthesis choice is the most optimal for any individual patient, while also ensuring adequate long-term durability of these approaches to patients with aortic valve disease.

\section{Expert opinion: sutureless/rapid deployment prostheses use: what are the doubts we still have?}

\section{Giuseppe Santarpino}

Already from the first studies published in 2011, the sutureless/rapid deployment prostheses have been greeted with skepticism; and some weaknesses have been underlined. The presented meta-analysis highlights the strengths of these devices, but it is necessary to "work" on the potential weak points in order to further extend the use of these prostheses.

First, the minimally invasive sutureless/rapid deployment aortic valve replacement is associated with higher risk for a postoperative permanent pacemaker. This incidence is well known and published for both prosthetic models (49) but, at the same time-it should be emphasized—tips and tricks (50) have been published to reduce this risk; and some papers have demonstrated a drastic improvement in this phenomenon over time (51).

Moreover, other studies highlight that the sutureless prostheses are associated with a higher risk of thrombocytopenia (52). In our opinion, these articles need some considerations for an "overall and integrated" choice of the prosthetic model to be used. The first consideration is that the recorded transient thrombocytopenia has no clinical impact. Conversely, the use of the sutureless prosthesis allows the implantation of a size-and therefore a better hemodynamic duration over time-significantly higher than that implantable with other prosthetic models. Therefore, there is a transitory and clinically irrelevant "disadvantage" versus a significant long-term "advantage" in hemodynamics (= patient's quality of life).

We instead believe that we could reason on how to associate the advantages of this prosthesis (e.g., stentless profile, ease to implant) with "saving" techniques on the platelets; in other words, making the sutureless procedure "totally minimally invasive" and not only due to a "small surgical incision" (e.g., association with minimally invasive extracorporeal circulation).

\section{Expert opinion: aortic valve replacement surgery: re-thinking clinical endpoints to further improve patient outcomes}

\section{Paolo Berretta, Marco Di Eusanio}

In the recent years, the treatment of aortic valve disease has been increasingly focused towards developing and popularizing less invasive procedures. By facilitating and shortening the valve implantation process, the sutureless and rapid deployment (SURD) valves have significantly contributed to simplify and promote minimally invasive approaches $(53,54)$. As confirmed in the present metaanalysis, minimally invasive aortic valve replacement (MIAVR) and SURD valves have described to be associated with equivalent very low mortality and stroke risk compared to conventional AVR. These well-established excellent results raise the question of how we can further improve AVR surgery. In this respect, secondary clinical endpoints such as the incidence of minor postoperative complications, reduced trauma, rapid recovery, quality of life and cosmesis should become key elements to evaluate the results of valve interventions. Multiple studies have demonstrated that MI-AVR provides superior outcomes 
in terms of reduction of postoperative complication rates and transfusion requirements, decreased length of postoperative stay, and patient satisfaction (55). In the present meta-analysis, Woldendorp et al. revealed that the use of either a less invasive approach and/or SURD valves is associated with reduced perioperative morbidity and faster recovery compared to conventional AVR. Patients receiving MI-AVR and/or SURD-AVR experienced a significantly lower incidence of postoperative atrial fibrillation, shorter ventilation time and reduced hospital stay. These findings confirm that less invasive approaches and SURD valves should represent essential tools in the field of modern valve surgery, and the implementation of such techniques and technologies should be considered a fundamental step to further improve patient clinical outcomes.

\section{Expert opinion: minimally invasive and sutureless: the way to go}

\section{Bart Meuris}

Surgeons and complex analyses of large data sets haven't always been a great marriage, but look...times they are a changing. In the midst of a worldwide rush towards transcatheter treatment for aortic valve disease, Woldendorp et al. provide excellent data on several currently existing options for surgical aortic valve replacement (SAVR). Guided by experts in minimally invasive techniques, they performed a meta-analysis gathering data from almost 9,000 patients. It is clear that both minimally invasive aortic valve surgery (MiAVR), as well as the use of sutureless valves (SuAVR), provide patients with a safe, stable and reproducible result. Looking at hard and relevant outcomes such as early mortality and postoperative stroke, the figures look far better than was obtained in the surgical arms of recent randomized trials (56). Combining both techniques (MiSuAVR) probably brings together the best of two worlds, although the volume in patients isn't there yet to demonstrate this clearly. We all should take these excellent outcomes in mind before referring all patients with aortic stenosis towards some kind of percutaneous therapy (TAVR).

Concerning sutureless valves specifically, the significantly lower rate of postoperative atrial fibrillation (AF) is important, since this will lower the overall risk of major thrombo-embolic events in the whole postoperative phase. This finding on AF has been confirmed by the results of the PERSIST-AVR trial (data shared at the latest (online) AATS meeting). The reduced cardio-pulmonary bypass and cross-clamp times ( $>25$ min of reduction) are important for our-increasingly older and sicker-patients, and these shorter times have many positive side-effects: less injury, less inflammation, reduced hospital stay, less wound infections, less acute kidney injury, lower ventilation times and - most relevant to all—early mortality are all reduced, but some outcomes need even larger data sets to obtain statistical significance. The issue of higher pacemaker need in sutureless valves will disappear due to better knowledge about sizing and positioning of these prostheses. And last but not least, the long-term follow is coming. We have been using sutureless valves since 2007 and the number of patients with more than a decade of follow up is growing.

Sutureless valves offer speed and safety. Clinical relevance is already there, statistical significance will be obtained in the near future. In combination with minimal access, this is the way to go.

\section{Expert opinion: minimally invasive sutureless aortic valve replacement: on the right track}

\section{Alfredo Giuseppe Cerillo, Pierluigi Stefano, Niccolò Marchionni}

The meta-analysis of Woldendorp and colleagues, based on twenty-three papers and almost 9,000 patients, demonstrates excellent outcomes and a reduced incidence of postoperative atrial fibrillation in patients receiving sutureless or rapid deployment (SURD) valves. It also suggests a benefit in terms of late mortality and freedom from valve dysfunction. Still, it fails to show significant advantages in terms of hard outcomes (mortality, disease free survival) over conventional full sternotomy aortic valve replacement.

This issue is not new: despite the fact that minimally invasive sutureless aortic valve replacement (MiSuAVR) offers improved haemodynamics and reduced surgical trauma, a definitive evidence of its superiority over conventional AVR is lacking-and this is somewhat frustrating, especially if compared with the tremendous success of transcatheter aortic valve replacement (TAVR).

Diversely from ten years ago, several therapeutic options can now be offered to patients with aortic valve disease, each having specific advantages and drawbacks. SURD valves share some advantageous features with both sutured aortic bioprostheses and transcatheter heart valves (THV). However, they also share with THV's some important 
drawbacks. Being "valved stents", their sealing relies on oversizing, and their function may be heavily dependent upon the final stent geometry. For this reason, it is logical to assume that the SURD valves may be less effective when implanted in a suboptimal anatomy, and that this could jeopardize the obvious advantages offered by MiSuAVR.

MiSuAVR might be the best alternative to TAVR for many patients with a complex anatomy (small aortic annulus, bulky annular/left ventricular outflow tract calcifications, calcific aortic root, bicuspid aortic valves, low origin of the coronary arteries, valve-in-valve in bad targets). However, it can also expose patients to specific complications. As for TAVR, only a detailed pre-operative knowledge of the patients' anatomy can help to select the optimal candidates for MiSuAVR, and to choose the best surgical access and prosthesis size and brand for any given patient. We believe that selecting the right procedure for each individual patient according to the anatomy on cardiac CT should become mandatory: an anatomy-based approach could help to define the role of MiSuAVR compared to other treatment strategies. Large, prospective trials are needed to investigate the potential of SURD valves in specific patient subsets.

\section{Expert opinion: sutureless valves and smaller incisions: the paradox of choice}

\section{Jacqueline K. Olive, Tom C. Nguyen}

Today's cardiac surgeons have a wide range of therapies for severe aortic stenosis, including traditional full sternotomy aortic valve replacement (SAVR), minimally-invasive aortic valve replacement (MiAVR), sutureless/rapid-deployment AVR (SuAVR) via full-sternotomy, or minimally-invasive SuAVR (MiSuAVR). In a meta-analysis with over 8,700 patients, the investigators found that sutureless and minimally-invasive techniques demonstrate similar early survival outcomes and complication rates to SAVR, with added potential for decreased cardiopulmonary bypass, aortic cross-clamping, ventilation, and hospital length-ofstay durations.

Notably, these pooled data demonstrate the newer relative success of SuAVR. Numerous studies already support the greater adoption of MiAVR, which may be associated with better outcomes than SAVR when cumulatively accounting for mortality, adverse events, and hospital costs (23-25). This study interestingly reports that SuAVR elicits nearly equivalent outcomes to MiAVR, including 30 -day mortality (3.7\% vs. 1.8\%), stroke (1.0\% vs. $1.8 \%)$, major bleeding (5.3\% vs. $3.7 \%)$, and late mortality (8.9\% vs. $5.4 \%)$. Although the SuAVR cohort was small with a short follow-up period, nonetheless SuAVR, MiAVR and MiSuAVR can be considered as viable options after careful patient selection by an expert heart team.

The authors also reported that SuAVR may be most effective at reducing rates of postoperative atrial fibrillation (POAF), yet MiSuAVR actually resulted in a greater postoperative pacemaker requirement. As previously suggested, minimally-invasive surgery has demonstrated a decreased burden of POAF compared to SAVR. It is prudent not to exchange one morbidity for another by pushing for innovation in place of the standard of care or other vetted alternatives.

In summary, this study provides excellent much-needed analysis as AVR treatment options expand along with patient complexity. Individual patient selection remains critical given the significant heterogeneity between intervention groups, thus, the paradox of choice. Time will hopefully reveal critical late outcomes benefits for sutureless, minimally-invasive, and combined approaches.

\section{Expert opinion: sutureless/rapid deployment valve foster a new era in tailored approach to aortic valve replacement}

\section{Marco Solinas, Giacomo Bianchi}

In this issue of Annals of Cardiothoracic Surgery, Woldendorp et al. performed an elegant Bayesian network meta-analysis to compare the outcomes of the different surgical and valve approaches [sutureless/rapid deployment (RD) $v s$. stented] in aortic valve replacement (AVR).

The authors outline a reduction in the use of sutureless/ $\mathrm{RD}$ valves in the sternotomy approach (6.2\%), while in the minimally invasive surgery group these represent a quarter $(24.8 \%)$ of the prostheses.

The use of sutureless/RD valves in a conventional approach represent the best choice in terms of reduction of post-operative atrial fibrillation, lower incidence of pacemaker implantation, acute renal failure and bleeding events, reduction of cardiopulmonary bypass and cross clamp time, intensive care and total hospital stay. On the other hand, sutureless/RD valves in a minimallyinvasive approach represent the best option in terms of reduced mortality, surgical site complications, same as the aforementioned group, and are the best option in terms 
of shorter mechanical ventilation time. It is important to stress the concept of pacemaker incidence in the sutureless/ RD group (sutureless being $84.3 \%$ of the total), which can be determined by the very nature of self-expanding valves and an initial tendency to oversizing, as well as the implantation of these valves in patients with pre-existing conduction defects. In conclusion, this meta-analysis throws an important light on the patient selection characteristics, with the advantages of sutureless/RD valve substitutes and also that the minimally-invasive approach, which itself has a learning curve, should be used in Centers with extensive experience with a mentoring program in order not to blunt the advantages that strongly emerge from the literature and this article.

\section{Acknowledgments}

None.

\section{Footnote}

Conflicts of Interest: The authors have no conflicts of interest to declare.

Open Access Statement: This is an Open Access article distributed in accordance with the Creative Commons Attribution-NonCommercial-NoDerivs 4.0 International License (CC BY-NC-ND 4.0), which permits the noncommercial replication and distribution of the article with the strict proviso that no changes or edits are made and the original work is properly cited (including links to both the formal publication through the relevant DOI and the license). See: https://creativecommons.org/licenses/by-nc-nd/4.0/.

\section{References}

1. Carabello BA. Introduction to aortic stenosis. Circ Res 2013;113:179-85.

2. Murtuza B, Pepper JR, DeL Stanbridge R, et al. Minimal Access Aortic Valve Replacement: Is It Worth It? Ann Thorac Surg 2008;85:1121-31.

3. Pisano C, Totaro P, Triolo OF, et al. Advantages of Minimal Access Versus Conventional Aortic Valve Replacement in Elderly or Severely Obese Patients. Innovations 2017;12:102-8.

4. ElBardissi AW, Shekar P, Couper GS, et al. Minimally invasive aortic valve replacement in octogenarian, highrisk, transcatheter aortic valve implantation candidates. J
Thorac Cardiovasc Surg 2011;141:328-35.

5. Glauber M, Miceli A. Minimally invasive aortic valve replacement with sutureless valve is the appropriate treatment option for high-risk patients and the "real alternative" to transcatheter aortic valve implantation. J Thorac Cardiovasc Surg 2016;151:610-3.

6. Salis S, Mazzanti VV, Merli G, et al. Cardiopulmonary bypass duration is an independent predictor of morbidity and mortality after cardiac surgery. J Cardiothorac Vasc Anesth 2008;22:814-22.

7. Nissinen J, Biancari F, Wistbacka JO, et al. Safe time limits of aortic cross-clamping and cardiopulmonary bypass in adult cardiac surgery. Perfusion 2009;24:297-305.

8. Brown WR, Moody DM, Challa VR, et al. Longer Duration of Cardiopulmonary Bypass Is Associated With Greater Numbers of Cerebral Microemboli. Stroke 2000;31:707-13.

9. Kumar AB, Suneja M, Bayman EO, et al. Association between postoperative acute kidney injury and duration of cardiopulmonary bypass: a meta-analysis. J Cardiothorac Vasc Anesth 2012;26:64-9.

10. Mariscalco G, Lorusso R, Dominici C, et al. Acute Kidney Injury: A Relevant Complication After Cardiac Surgery. Ann Thorac Surg 2011;92:1539-47.

11. Axtell AL, Fiedler AG, Melnitchouk S, et al. Correlation of cardiopulmonary bypass duration with acute renal failure after cardiac surgery. J Thorac Cardiovasc Surg 2019. [Epub ahead of print].

12. Borger MA, Moustafine V, Conradi L, et al. A Randomized Multicenter Trial of Minimally Invasive Rapid Deployment Versus Conventional Full Sternotomy Aortic Valve Replacement. Ann Thorac Surg 2015;99:17-25.

13. Ai L, Chen H, Lin V, et al. Rapid Deployment Aortic Valves Deliver Superior Hemodynamic Performance in Vitro. Innovations 2017;12:338-45.

14. Shrestha M, Fischlein T, Meuris B, et al. European multicentre experience with the sutureless Perceval valve: clinical and haemodynamic outcomes up to 5 years in over 700 patients. Eur J Cardiothorac Surg 2016;49:234-41.

15. Moher D, Liberati A, Tetzlaff J, et al. Preferred reporting items for systematic reviews and meta-analyses: the PRISMA statement. BMJ 2009;339:b2535-5.

16. Hozo SP, Djulbegovic B, Hozo I. Estimating the mean and variance from the median, range, and the size of a sample. BMC Med Res Methodol 2005;5:13.

17. Wan X, Wang W, Liu J, et al. Estimating the sample mean and standard deviation from the sample size, median, range 
and/or interquartile range. BMC Med Res Methodol 2014;14:135.

18. Luo D, Wan X, Liu J, et al. Optimally estimating the sample mean from the sample size, median, mid-range, and/or mid-quartile range. Stat Methods Med Res 2018;27:1785-805.

19. White IR. Network Meta-analysis. Stata J 2015;15:951-85.

20. Brown S, Hutton B, Clifford T, et al. A MicrosoftExcel-based tool for running and critically appraising network meta-analyses - an overview and application of NetMetaXL. Syst Rev 2014;3:110.

21. Bonacchi M, Prifti E, Giunti G, et al. Does ministernotomy improve postoperative outcome in aortic valve operation? A prospective randomized study. Ann Thorac Surg 2002;73:460-5; discussion 465-6.

22. Khoshbin E, Prayaga S, Kinsella J, et al. Ministernotomy for aortic valve replacement reduces the length of stay in the cardiac intensive care unit: metaanalysis of randomised controlled trials. BMJ Open 2011;1:e000266-6.

23. Ghanta RK, Lapar DJ, Kern JA, et al. Minimally invasive aortic valve replacement provides equivalent outcomes at reduced cost compared with conventional aortic valve replacement: A real-world multi-institutional analysis. J Thorac Cardiovasc Surg 2015;149:1060-5.

24. Gilmanov D, Bevilacqua S, Murzi M, et al. Minimally Invasive and Conventional Aortic Valve Replacement: A Propensity Score Analysis. Ann Thorac Surg 2013;96:837-43.

25. Bowdish ME, Hui DS, Cleveland JD, et al. A comparison of aortic valve replacement via an anterior right minithoracotomy with standard sternotomy: a propensity score analysis of 492 patients. Eur J Cardiothorac Surg 2016;49:456-63.

26. Gilmanov D, Farneti PA, Ferrarini M, et al. Full sternotomy versus right anterior minithoracotomy for isolated aortic valve replacement in octogenarians: a propensity-matched study. Interact Cardiovasc Thorac Surg 2015;20:732-41.

27. Del Giglio M, Mikus E, Nerla R, et al. Right anterior mini-thoracotomy vs. conventional sternotomy for aortic valve replacement: a propensity-matched comparison. J Thorac Dis 2018;10:1588-95.

28. Antonides CFJ, Mack MJ, Kappetein AP. Approaches to the Role of The Heart Team in Therapeutic Decision Making for Heart Valve Disease. Structural Heart 2017;1:249-55.

29. Borger MA, Rao V, Weisel RD, et al. Deep sternal wound infection: risk factors and outcomes. Ann Thorac Surg 1998;65:1050-6.

30. De Feo M, Renzulli A, Ismeno G, et al. Variables predicting adverse outcome in patients with deep sternal wound infection. Ann Thorac Surg 2001;71:324-31.

31. Parisian Mediastinitis Study Group. Risk factors for deep sternal wound infection after sternotomy: a prospective, multicenter study. J Thorac Cardiovasc Surg 1996;111:1200-7.

32. Toumpoulis IK, Anagnostopoulos CE, Derose JJ, et al. The impact of deep sternal wound infection on longterm survival after coronary artery bypass grafting. Chest 2005;127:464-71.

33. Folliguet TA, Laborde F, Zannis K, et al. Sutureless Perceval Aortic Valve Replacement: Results of Two European Centers. Ann Thorac Surg 2012;93:1483-8.

34. D'Onofrio A, Messina A, Lorusso R, et al. Sutureless aortic valve replacement as an alternative treatment for patients belonging to the "gray zone" between transcatheter aortic valve implantation and conventional surgery: A propensity-matched, multicenter analysis. J Thorac Cardiovasc Surg 2012;144:1010-6.

35. Vogt F, Pfeiffer S, Dell'Aquila AM, et al. Sutureless aortic valve replacement with Perceval bioprosthesis: are there predicting factors for postoperative pacemaker implantation? Interact Cardiovasc Thorac Surg 2016;22:253-8.

36. Forcillo J, Bouchard D, Nguyen A, et al. Perioperative outcomes with sutureless versus stented biological aortic valves in elderly persons. J Thorac Cardiovasc Surg 2016;151:1629-36.

37. Nazif TM, Dizon JM, Hahn RT, et al. Predictors and clinical outcomes of permanent pacemaker implantation after transcatheter aortic valve replacement: the PARTNER (Placement of AoRtic TraNscathetER Valves) trial and registry. JACC Cardiovasc Interv 2015;8:60-9.

38. Glauber M, Di Bacco L, Cuenca J, et al. Minimally Invasive Aortic Valve Replacement with Sutureless Valves: Results From an International Prospective Registry. Innovations (Phila) 2020;15:120-30.

39. Vogt F, Moscarelli M, Nicoletti A, et al. Sutureless Aortic Valve and Pacemaker Rate: From Surgical Tricks to Clinical Outcomes. Ann Thorac Surg 2019;108:99-105.

40. Kapadia SR, Wazni O, Krishnaswamy A. Pacemaker Implantation After TAVR. JACC Cardiovasc Imaging 2017;10:1148-50.

41. Rodés-Cabau J. Optimizing Valve Implantation Depth to Win the Battle Against Conduction Disturbances Post- 
TAVR. JACC Cardiovasc Interv 2019;12:1808-10.

42. Jilaihawi H, Zhao Z, Du R, et al. Minimizing Permanent Pacemaker Following Repositionable Self-Expanding Transcatheter Aortic Valve Replacement. JACC Cardiovasc Interv 2019;12:1796-807.

43. Ensminger S, Fujita B, Bauer T, et al. Rapid Deployment Versus Conventional Bioprosthetic Valve Replacement for Aortic Stenosis. J Am Coll Cardiol 2018;71:1417-28.

44. Paparella D, Yau TM, Young E. Cardiopulmonary bypass induced inflammation: pathophysiology and treatment. An update. Eur J Cardiothorac Surg 2002;21:232-44.

45. Jakubová M, Mitro P, Stancak B, et al. The occurrence of postoperative atrial fibrillation according to different surgical settings in cardiac surgery patients. Interact Cardiovasc Thorac Surg 2012;15:1007-12.

46. Greenberg JW, Lancaster TS, Schuessler RB, et al. Postoperative atrial fibrillation following cardiac surgery: a persistent complication. Eur J Cardiothorac Surg 2017;52:665-72.

47. Neely RC, Boskovski MT, Gosev I, et al. Minimally invasive aortic valve replacement versus aortic valve replacement through full sternotomy: the Brigham and Women's Hospital experience. Ann Cardiothorac Surg 2015;4:38-48.

48. Gilmanov D, Miceli A, Ferrarini M, et al. Aortic Valve Replacement Through Right Anterior Minithoracotomy: Can Sutureless Technology Improve Clinical Outcomes? Ann Thorac Surg 2014;98:1585-92.

49. Coti I, Schukro C, Drevinja F, et al. Conduction disturbances following surgical aortic valve replacement with a rapid-deployment bioprosthesis. J Thorac

Cite this article as: Woldendorp K, Doyle MP, Bannon PG, Misfeld M, Yan TD, Santarpino G, Berretta P, Di Eusanio M, Meuris B, Cerillo AG, Stefano P, Marchionni N, Olive JK, Nguyen TC, Solinas M, Bianchi G. Aortic valve replacement using stented or sutureless/rapid deployment prosthesis via either full-sternotomy or a minimally invasive approach: a network meta-analysis. Ann Cardiothorac Surg 2020;9(5):347363. doi: $10.21037 /$ acs-2020-surd-17
Cardiovasc Surg 2020. [Epub ahead of print].

50. Vogt F, Dell'Aquila AM, Santarpino G. How to Prevent Pacemaker Implantation After Sutureless Aortic Valve Replacement: Tips and Tricks. Ann Thorac Surg 2017;104:720-1.

51. Berretta P, Arzt S, Fiore A, et al. Current trends of sutureless and rapid deployment valves: an 11-year experience from the Sutureless and Rapid Deployment International Registry. Eur J Cardiothorac Surg 2020. [Epub ahead of print].

52. Stegmeier P, Schlömicher M, Stiegler H, et al. Thrombocytopenia after implantation of the Perceval S aortic bioprosthesis. J Thorac Cardiovasc Surg 2020;160:61-8.

53. Berretta $\mathrm{P}$, Arzt S, Fiore A, et al. Current trends of sutureless and rapid deployment valves: an 11-year experience from the Sutureless and Rapid Deployment International Registry. Eur J Cardiothorac Surg 2020. [Epub ahead of print].

54. Berretta P, Andreas M, Carrel TP, et al. Minimally invasive aortic valve replacement with sutureless and rapid deployment valves: a report from an international registry (Sutureless and Rapid Deployment International Registry)†. Eur J Cardiothorac Surg 2019;56:793-9.

55. Phan K, Xie A, Di Eusanio M, et al. A meta-analysis of minimally invasive versus conventional sternotomy for aortic valve replacement. Ann Thorac Surg 2014;98:1499-511.

56. Mack MJ, Leon MB, Thourani VH, et al. Transcatheter Aortic-Valve Replacement with a Balloon-Expandable Valve in Low-Risk Patients. N Engl J Med 2019;380:1695-705. 


\section{Search strategy}

((((AVR) OR aortic valve replacement) OR SAVR)) AND ((((()inimally-invasive) OR mini) OR hemi sternotomy) OR right thoracotomy) OR sutureless) OR rapid deployment prosthesis).

\section{References}

57. Pollari F, Santarpino G, Dell'Aquila AM, et al. Better short-term outcome by using sutureless valves: a propensity-matched score analysis. Ann Thorac Surg 2014;98:611-6; discussion 616-7.

58. Dalén M, Biancari F, Rubino AS, et al. Ministernotomy versus full sternotomy aortic valve replacement with a sutureless bioprosthesis: a multicenter study. Ann Thorac Surg 2015;99:524-30.

59. Vola M, Campisi S, Gerbay A, et al. Sutureless prostheses and less invasive aortic valve replacement: just an issue of clamping time? Ann Thorac Surg 2015;99:1518-23.

60. Smith AL, Shi WY, Rosalion A, et al. Rapid-Deployment Versus Conventional Bio-Prosthetic Aortic Valve Replacement. Heart Lung Circ 2017;26:187-93.

61. Hiraoka A, Totsugawa T, Kuinose M, et al. Propensity Score-Matched Analysis of Minimally Invasive Aortic Valve Replacement. Circ J 2014;78:2876-81.

62. Ruttmann E, Gilhofer TS, Ulmer H, et al. Propensity score-matched analysis of aortic valve replacement by mini-thoracotomy. J Heart Valve Dis 2010;19:606-14.

63. Casha AR, Manché A, Camilleri L, et al. Sutureless Perceval aortic valve implantation compared with conventional Mitroflow valve replacement. Indian J Thorac Cardiovasc Surg 2017;34:109-15.
64. Dalén M, Biancari F, Rubino AS, et al. Aortic valve replacement through full sternotomy with a stented bioprosthesis versus minimally invasive sternotomy with a sutureless bioprosthesis. Eur J Cardiothorac Surg 2016;49:220-7.

65. A comparison of aortic valve replacement via an anterior right minithoracotomy with standard sternotomy: a propensity score analysis of 492 patients. Eur J Cardiothorac Surg 2016;49:456-63.

66. Aliahmed HMA, Karalius R, Valaika A, et al. Efficacy of Aortic Valve Replacement through Full Sternotomy and Minimal Invasion (Ministernotomy). Medicina (Kaunas) 2018;54:26.

67. Mataraci I, Hanedan MO, Sayar U, et al. Early outcomes of the sutureless aortic valves versus conventional stented bioprosthetic valves. Turk Gogus Kalp Dama 2016;24:240-7.

68. Masiello P, Coscioni E, Panza A, et al. Surgical results of aortic valve replacement via partial upper sternotomy: comparison with median sternotomy. Cardiovasc Surg 2002;10:333-8.

69. Hanedan MO, Yuruk MA, Parlar AI, et al. Sutureless versus Conventional Aortic Valve Replacement: Outcomes in 70 High-Risk Patients Undergoing Concomitant Cardiac Procedures. Tex Heart Inst J 2018;45:11-6.

70. Nguyen TC, Thourani VH, Pham JQ, et al. Traditional Sternotomy Versus Minimally Invasive Aortic Valve Replacement in Patients Stratified by Ejection Fraction. Innovations (Phila) 2017;12:33-40.

71. Mujtaba SS, Ledingham SM, Shah AR, et al. Aortic Valve Replacement with a Conventional Stented Bioprosthesis versus Sutureless Bioprosthesis: a Study of 763 Patients. Braz J Cardiovasc Surg 2018;33:122-8. 
Cardiopulmonary Bypass Time

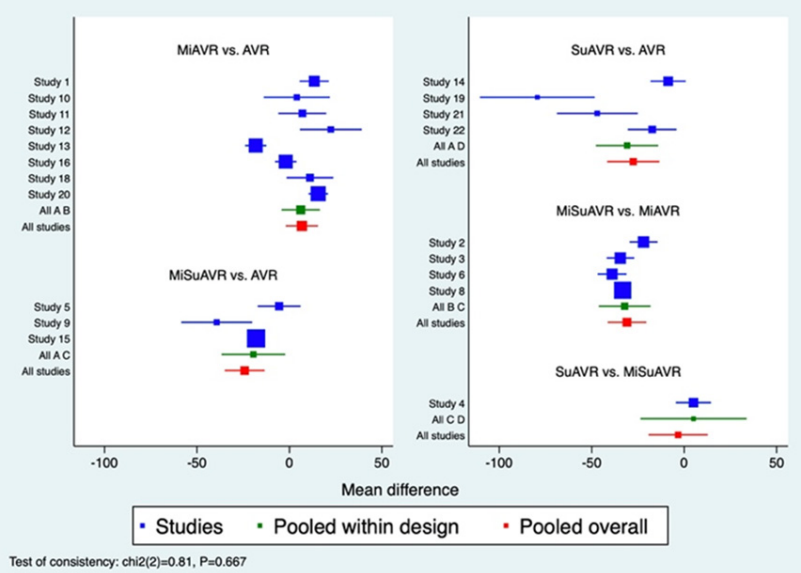

Major Bleeding

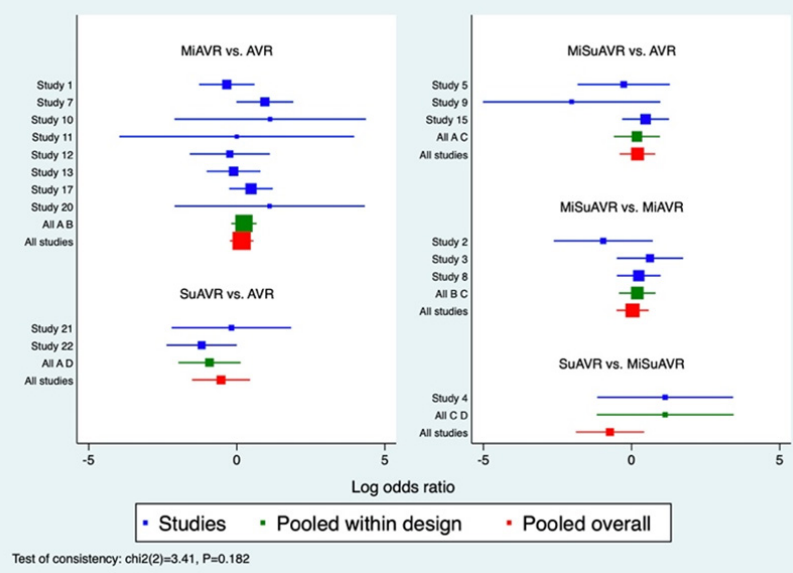

Surgical Site Complication

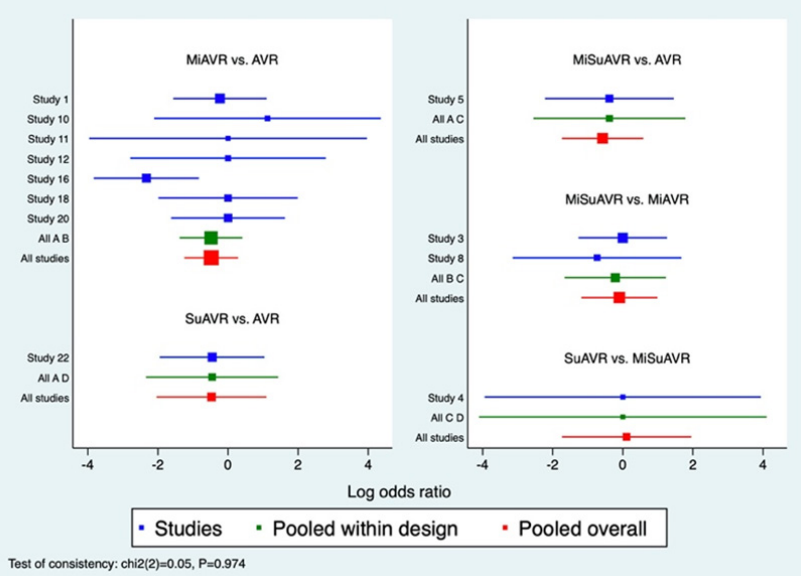

Cross-Clamp Time

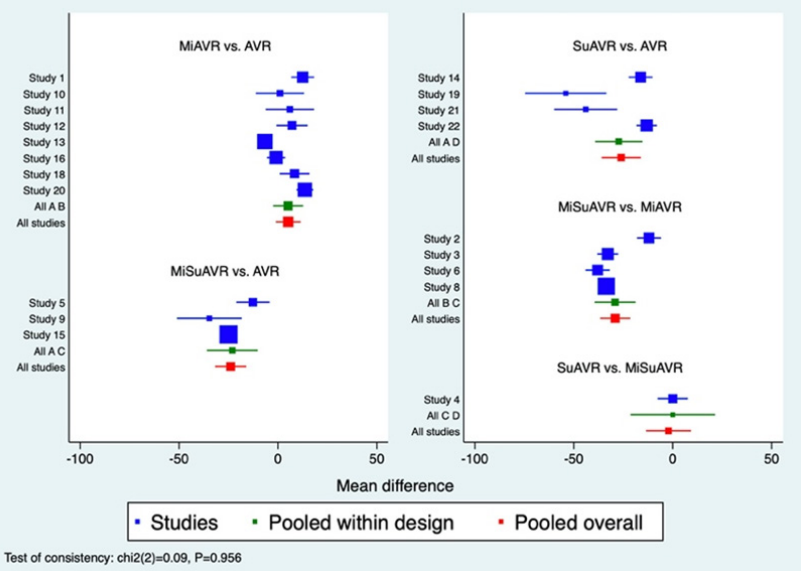

Acute Kidney Injury

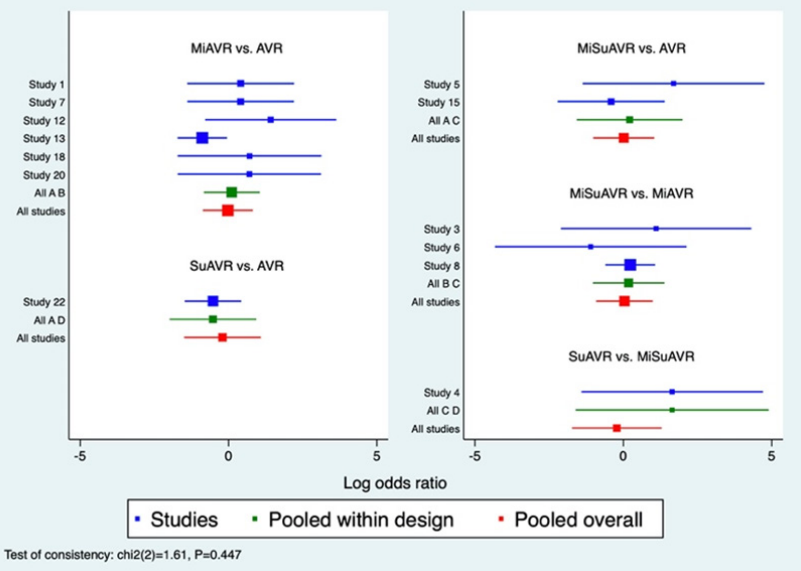

Intensive Care Stay (days)

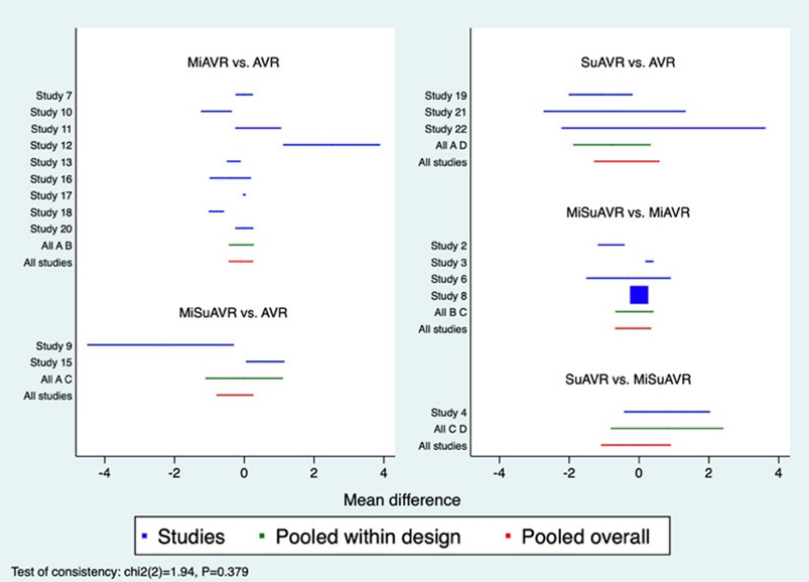

Figure S1 Forest plots for AVR by surgical approach and prosthesis examining perioperative outcomes. AVR, full sternotomy aortic valve replacement; MiAVR, minimally invasive AVR; SuAVR, sutureless AVR; MiSuAVR, minimally invasive sutureless AVR. 


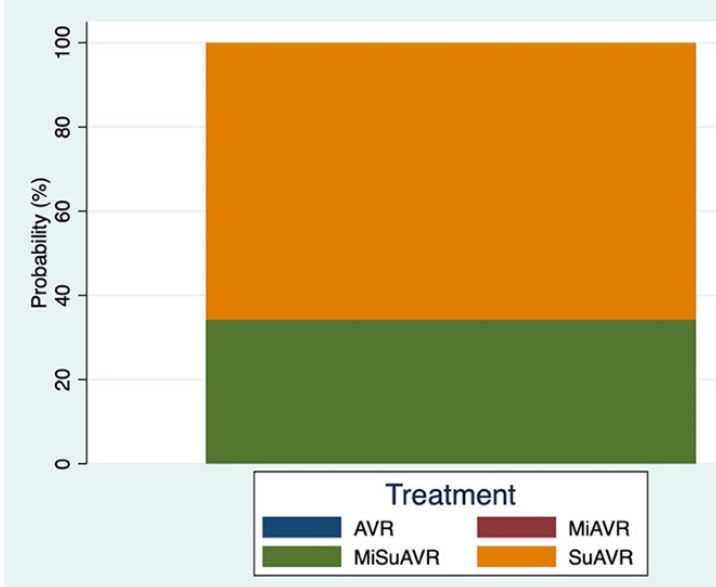

Major Bleeding

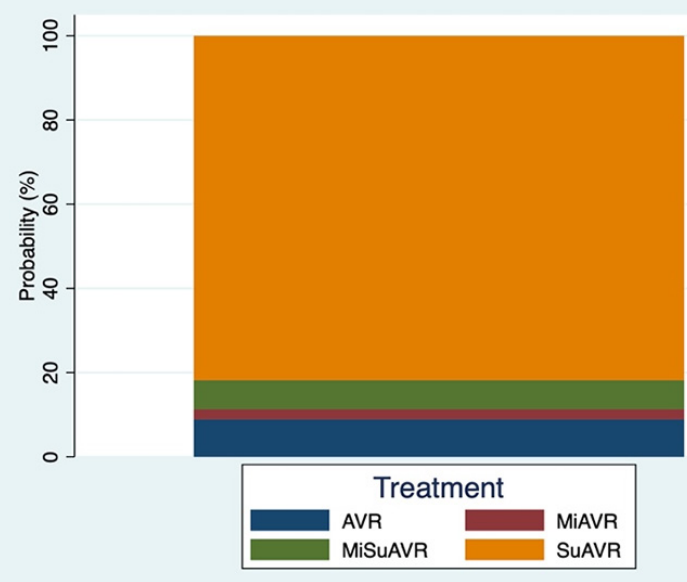

Surgical Site Complication

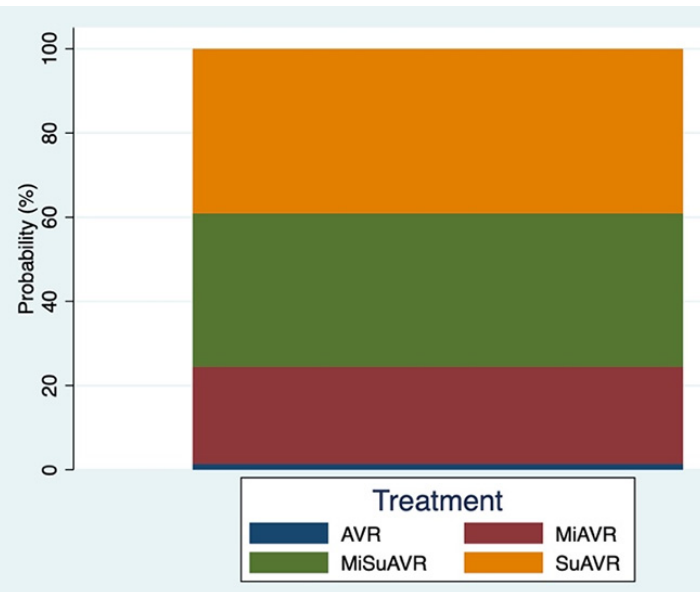

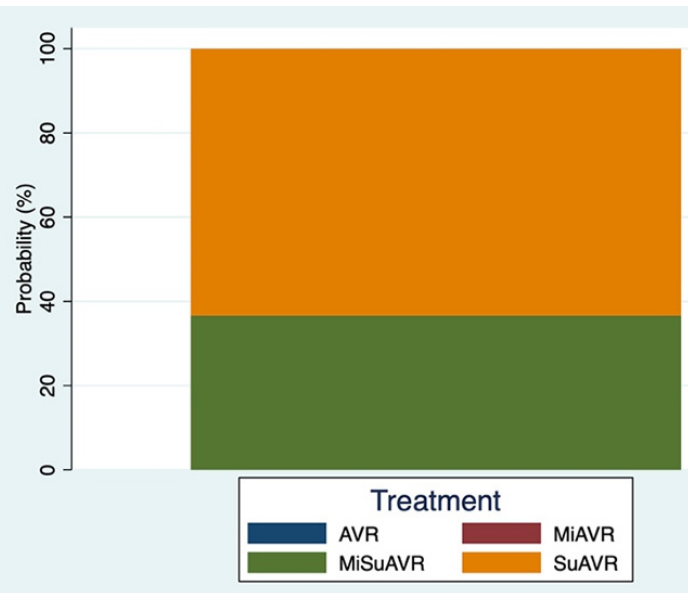

Acute Kidney Injury

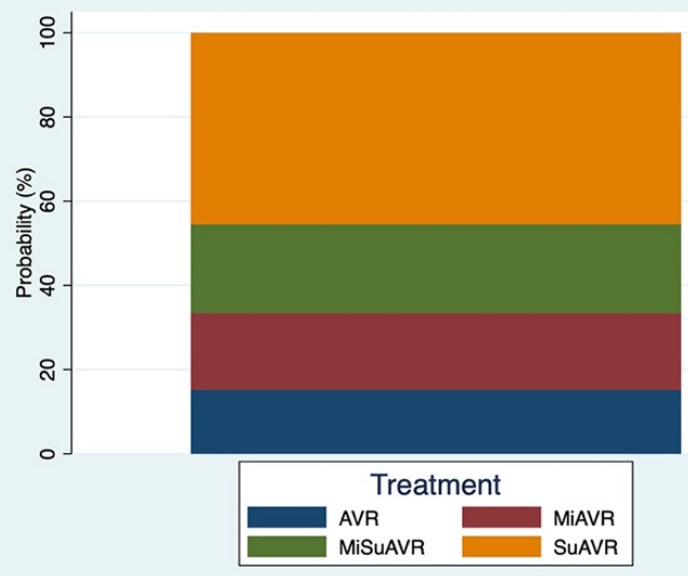

Intensive Care Stay (days)

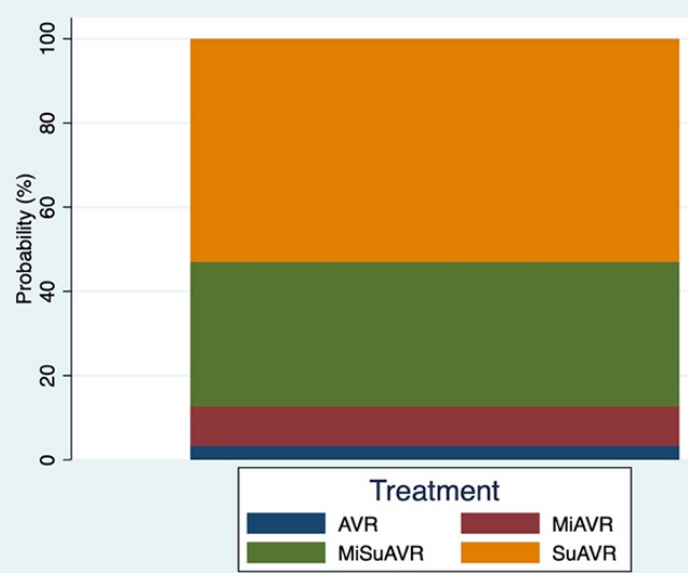

Figure S2 Rankograms for AVR by surgical approach and prosthesis examining perioperative outcomes. For example, if suAVR accounts for $40 \%$ of the rankogram, then it has a $40 \%$ probability of being the best-ranked treatment option for that particular outcome. AVR, full sternotomy aortic valve replacement; MiAVR, minimally invasive AVR; SuAVR, sutureless AVR; MiSuAVR, minimally invasive sutureless AVR. 


\begin{tabular}{|c|c|c|c|c|c|c|c|c|c|}
\hline \multirow{2}{*}{ Study } & \multirow{2}{*}{ Year } & \multicolumn{4}{|c|}{ Approach (n) } & \multirow{2}{*}{ Location } & \multirow{2}{*}{ Period } & \multirow{2}{*}{$\begin{array}{l}\text { Study } \\
\text { type }\end{array}$} & \multirow{2}{*}{ Risk score* } \\
\hline & & SAVR & SuAVR & MiAVR & MiSuAVR & & & & \\
\hline Gilmanov (24) & 2013 & 182 & 0 & 182 & 0 & Italy & 2004-2011 & $\mathrm{RM}$ & Log ES I \\
\hline Pollari (57) & 2014 & 0 & 0 & 82 & 82 & Germany & 2010-2013 & $\mathrm{RM}$ & Log ES I \\
\hline Gilmanov (48) & 2014 & 0 & 0 & 133 & 133 & Italy & 2004-2014 & $\mathrm{RM}$ & Log ES I \\
\hline Dalen (58) & 2015 & 0 & 78 & 0 & 189 & Sweden & 2007-2014 & $\mathrm{RM}$ & ES II \\
\hline Borger (12) & 2015 & 48 & 0 & 0 & 46 & Germany & 2012-2013 & $\mathrm{RCT}$ & $\mathrm{N} / \mathrm{A}$ \\
\hline Vola (59) & 2015 & 0 & 0 & 42 & 41 & France & 2009-2012 & $\mathrm{RM}$ & ES I \\
\hline Ghanta (23) & 2015 & 289 & 0 & 289 & 0 & USA & 2011-2013 & $\mathrm{RM}$ & STS PROM \\
\hline Glauber (5) & 2016 & 0 & 0 & 291 & 302 & Italy & 2004-2014 & $\mathrm{RM}$ & Log ES I \\
\hline Smith (60) & 2017 & 556 & 0 & 0 & 41 & Australia & 2008-2015 & $\mathrm{RM}$ & N/A \\
\hline Hiraoka (61) & 2014 & 194 & 0 & $88^{\#}$ & 0 & Japan & 2007-2012 & $\mathrm{RM}$ & STS PROM \\
\hline Ruttmann (62) & 2010 & 87 & 0 & 87 & 0 & Austria & 2006-2009 & $\mathrm{RM}$ & ES I \\
\hline Neely (47) & 2014 & 552 & 0 & 552 & 0 & USA & 2002-2014 & $\mathrm{RM}$ & N/A \\
\hline Casha (63) & 2018 & 20 & 20 & 0 & 0 & Malta & & $\mathrm{RM}$ & ES I \\
\hline Dalen (64) & 2016 & 383 & 0 & 0 & 182 & EU & 2007-2014 & $\mathrm{RM}$ & Log ES I \\
\hline Bowdish (65) & 2015 & 198 & 0 & 294 & 0 & USA & 1999-2013 & $\mathrm{RM}$ & N/A \\
\hline Giglio (27) & 2018 & 363 & 0 & 363 & 0 & Italy & 2010-2016 & $\mathrm{RM}$ & ES I \\
\hline Aliahmed (66) & 2018 & 356 & 0 & 70 & 0 & Lithuania & 2011-2016 & RM & ES II \\
\hline Mataraci (67) & 2016 & 25 & 21 & 0 & 0 & Turkey & 2009-2014 & $\mathrm{RM}$ & ES II \\
\hline Masiello (68) & 2002 & 100 & 0 & 100 & 0 & Italy & 1997-1999 & $\mathrm{RM}$ & N/A \\
\hline Hanedan (69) & 2018 & 32 & 38 & 0 & 0 & Turkey & 2009-2016 & $\mathrm{RM}$ & Log ES I \\
\hline Nguyen $^{a}(70)$ & 2017 & 35 & 0 & 35 & 0 & USA & 2011-2014 & $\mathrm{RM}$ & STS PROM \\
\hline Nguyen $^{\mathrm{b}}(70)$ & 2017 & 377 & 0 & 377 & 0 & USA & 2011-2014 & $\mathrm{RM}$ & STS PROM \\
\hline Mujtaba (71) & 2017 & 624 & 139 & 0 & 0 & Ireland & 2011-2016 & $\mathrm{RM}$ & ES II \\
\hline
\end{tabular}

a, LVEF <40\%; ' , LVEF >40\%; ", divided into 62 via RT and 26 via HS; *, defines the risk score used as part of the propensity matching algorithm. LVEF, left ventricular ejection fraction; SAVR, full sternotomy aortic valve replacement; SuAVR, sutureless aortic valve replacement via full sternotomy; MiAVR, minimally invasive aortic valve replacement; MiSuAVR, sutureless aortic valve replacement via minimally invasive procedure; RCT, randomised controlled trial; RM, retrospective matched; ES I, EuroSCORE I; Log ES I, logistic EuroSCORE I; ES II, EuroSCORE II; STS PROM, Society of Thoracic Surgeons Predicted Risk of Mortality. 


\begin{tabular}{|c|c|c|c|c|}
\hline Mortality (\%) & 0.5 & 16.7 & 39.9 & 42.9 \\
\hline Stroke (\%) & 7.0 & 62.3 & 14.4 & 16.3 \\
\hline Postoperative atrial fibrillation (\%) & 0.0 & 0.3 & 85.7 & 14.0 \\
\hline Acute kidney injury (\%) & 15.2 & 18.2 & 45.5 & 21.1 \\
\hline Major bleeding (\%) & 9.2 & 2.8 & 81.4 & 6.6 \\
\hline Surgical site complication (\%) & 1.4 & 23.1 & 39.1 & 36.4 \\
\hline CPB time (min) & 0.0 & 0.0 & 65.8 & 34.2 \\
\hline ICU LOS (days) & 3.3 & 9.4 & 53.0 & 34.3 \\
\hline Hospital LOS (days) & 0.0 & 1.7 & 63.9 & 34.4 \\
\hline
\end{tabular}

